\title{
A robust TDP-43 knock-in mouse model of ALS
}

\author{
Shih-Ling Huang ${ }^{1,2,3}$, Lien-Szu Wu ${ }^{1,3}$, Min Lee ${ }^{1}$, Chin-Wen Chang ${ }^{1}$, Wei-Cheng Cheng ${ }^{1}$, Yu-Sheng Fang ${ }^{4}$, \\ Yun-Ru Chen ${ }^{4}$, Pei-Lin Cheng ${ }^{1}$ and Che-Kun James Shen ${ }^{1,2,3^{*}}$
}

\begin{abstract}
Amyotrophic lateral sclerosis (ALS) is a fatal, adult-onset degenerative disorder of motor neurons. The diseased spinal cord motor neurons of more than $95 \%$ of amyotrophic lateral sclerosis (ALS) patients are characterized by the mis-metabolism of the RNA/DNA-binding protein TDP-43 (ALS-TDP), in particular, the presence of cytosolic aggregates of the protein. Most available mouse models for the basic or translational studies of ALS-TDP are based on transgenic overexpression of the TDP-43 protein. Here, we report the generation and characterization of mouse lines bearing homologous knock-in of fALS-associated mutation A315T and SALS-associated mutation N390D, respectively. Remarkably, the heterozygous TDP-43 (N390D/+) mice but not those heterozygous for the TDP-43 (A315T/+) mice develop a full spectrum of ALS-TDP-like pathologies at the molecular, cellular and behavioral levels. Comparative analysis of the mutant mice and spinal cord motor neurons (MN) derived from their embryonic stem (ES) cells demonstrates that different ALS-associated TDP-43 mutations possess critical ALS-causing capabilities and pathogenic pathways, likely modified by their genetic background and the environmental factors. Mechanistically, we identify aberrant RNA splicing of spinal cord $B C l-2$ pre-mRNA and consequent increase of a negative regulator of autophagy, BCl-2, which correlate with and are caused by a progressive increase of TDP-43, one of the early events associated with ALS-TDP pathogenesis, in the spinal cord of TDP-43 (N390D/+) mice and spinal cord MN derived from their ES cells. The TDP-43 (N390D/+) knock-in mice appear to be an ideal rodent model for basic as well as translational studies of ALS- TDP.
\end{abstract}

Keywords: Amyotrophic lateral sclerosis (ALS), TAR DNA-binding protein 43 (TDP-43), Homologous knock-in mouse models with ALS-associated TDP-43 mutations, ALS-TDP pathogenesis, Autonomous spinal cord motor neuron degeneration, Mis-splicing of $\mathrm{BCl}-2$ pre-mRNA

\section{Introduction}

While the genetic basis of $80 \%$ of ALS is unknown, at least 31 genes, including SOD1 and TARDBP encoding the RNA/DNA-binding protein TDP-43, with mutations associated with ALS have been identified [13, 37]. In particular, a total of more than 50 missense mutations have been identified in the TARDBP gene through genetic analysis a number of familial and sporadic ALS cases [10]. Significantly, more than $95 \%$ of all ALS patients (ALS-TDP) are characterized by enhanced cleavage of TDP-43 to generate TDP-35/ TDP-25 fragments, by

\footnotetext{
* Correspondence: ckshen@gate.sinica.edu.tw

${ }^{1}$ Institute of Molecular Biology, Academia Sinica, Taipei 11529, Taiwan,

Republic of China

${ }^{2}$ Institute of Molecular Medicine, College of Medicine, National Taiwan

University, Taipei 10002, Taiwan, Republic of China

Full list of author information is available at the end of the article
}

accumulation of ubiquitinated TDP-43/phosphorylated TDP-43, and by formation of ubiquitin(+), TDP-43(+) aggregates in the cytosol [38, 48].

TDP-43 is a ubiquitously expressed heterogeneous nuclear ribonucleoprotein (hnRNP) protein that localized primarily in the nucleus and required for multiple cellular pathways [11, 36, 38, 69] including RNA metabolism and translation. Given these ubiquitous functions, aberrant expression of TDP-43 is likely to lead to multiple pathological consequences. Indeed, depletion of TDP-43 results in early embryonic lethality in mice [40, 76], promotes cellular deficits such as the impairment of autophagy through down-regulation of Atg7 [8] and alteration of fat metabolism via suppression of Tbc1d1 [14], and causes ALS-like phenotypes in mice [74]. Furthermore, under pathologic conditions, the total amount of TDP- 43 in the

(c) The Author(s). 2020 Open Access This article is distributed under the terms of the Creative Commons Attribution 4.0 International License (http://creativecommons.org/licenses/by/4.0/), which permits unrestricted use, distribution, and 
diseased cells is elevated $[6,34,39,48]$ in addition to its mislocalization in the cytosol and abnormal processing as mentioned above. As the pathological consequences of abnormally high levels of TDP-43, the biogenesis of many RNAs required for neural development and synaptic function are impaired [3,53]. Mutations in or depletion of TDP-43 also affect the translation and trafficking of neuronal mRNAs $[2,16,41,42]$.

In order to study ALS-TDP disease mechanisms, different animal models have been developed which display abnormal expression of TDP-43, either a decrease [74] or increase $[3,18,32,40]$ compared to the wild type mice. The transgenic mouse models that overexpress mutant TDP-43 under different neuronal promoters exhibited MND-like phenotype or cognition deficits with neuronal loss, and the hallmarks of TDP-43 proteinopathies [48]. This included mislocalizaiton of nuclear TDP-43, abnormal post-translational modifications, and formation of insoluble ubiquitin (+) / TDP-43 (+) inclusions [36]. Unfortunately, however, overexpression of wild type TDP-43 can also cause FTLD-TDP-like [63] or ALS-like pathogenesis of the transgenic mice [45]. It is therefore difficult to assess the pathological effects of the ALS-associated mutations of TDP-43 compared to wild type TDP-43 without appropriate control of their levels of overexpression, in transgenic animals or in transfected cell culture. Notably, White et al. [72] and Fratta et al. [26] have constructed mouse models by homologous knock-in of a ALS-FTD associated TDP-43 mutation, Q331K. However, mice with either one allele or both alleles mutated only exhibit subtle ALS-FTD-like phenotypes. More recently, Ebstein et al. [24] have reported the generation of another two mouse models with knock-in of fALS-associated TDP-43 mutations, M337 V and G298S, that show relatively mild motor neuron degeneration in homozygous mice, but not in heterozygous ones, after the age of 2-year old. Here, we report the generation and characterization of two mouse models, each bearing a single ALS-TDP associated TDP-43 knockin mutation (N390D or A315T). Remarkably, heterozygosity of the N390D mutation, but not A315T mutation, leads to a whole spectrum of male-dominant and age-dependent pathological features mimicking ALS-TDP.

\section{Materials and methods}

\section{Generation of TDP-43(A315T/+) and TDP-43 (N390D/+) knock-in mice}

Standard procedures were followed to generate mouse line carrying different Tardbp (TDP-43) mutations. The targeting vector carrying mutations (A315T or N390D) on exon 6 of Tardbp was cloned in the BAC clone RP23-364 M1 (Invitrogen) by using the counter-selection BAC modification kit (Gene bridges). For A315T, the nucleotide G at position 943 was substituted for A; the nucleotide A at position 1168 was substituted for $\mathrm{G}$ for N390D. A neo-resistant gene with loxP sequence cassette (PGK-neo cassette) was inserted into intron 4 of Tardbp for ES cell screening. Two independent targeted ES cell clones (\#125 and \#180 for A315T, \#108 and \#361 for N390D) were expanded and microinjected into C57BL/6 J (The Jackson Laboratory) blastocysts to generate the chimeric mice. Knock-in ES cells carrying A315T or N390D substitution in TDP-43 were identified by standard operating procedures of the Transgenic Core Facility of Institutional Molecular Biology, Academia Sinica. To remove the PGK-neo cassette from targeted Tardbp allele, the germline-transmitting F1 lines were crossed with Ella-Cre mice (Tg (EIIa-cre) C5379Lmgd; The Jackson Laboratory) expressing the Cre recombinase in the whole body. The genotypes of $\mathrm{A} 315 \mathrm{~T} /+$ or N390D/+ mice were verified by sequencing of cDNAs and genomic DNAs. All animals were maintained in a specific pathogen-free (SPF) environment under standard laboratory conditions and handled following the guidelines of the Institute Animal Care and Use Committee (IACUC) of Academia Sinica. The diseased mice were taken care of by the staff members including the feeding with soft food, spraying drinking water on the wall of cages, using soft materials for disable mice, etc.

The knock-in mice were genotyped by PCR using the forward primer 5'-GACCTCAACTGCTCTGCTTCTA CC-3' and the reverse primer 5'-AACGGAATCAA TCCTCTCCAGG-3'.

\section{Differentiation of mouse ESC into spinal cord motor neurons (MN) in culture}

TDP-43 knock-in mice were crossed with B6.Cg-Tg (Hlxb9GFP)1Tmj/J (Hb9:GFP; The Jackson Laboratory) transgenic mice to obtain offspring of the genotypes of TDP-43 (A315T/+); Hb9:GFP and TDP-43 (N390D/+); Hb9:GFP, respectively. The ESCs from 3.5 day embryo were cultured and differentiated into spinal $\mathrm{MN}$ as depicted in Fig. 4 following the protocols described by $[12,73]$. Briefly, in inductive phase, ESCs were cultured in differentiation medium (45\% Advanced DMEM/F12 (Gibico), 45\% Neurobasal (Gibico), 10\%l Knockout-SR (Gibico), $2 \mathrm{mM} \mathrm{L-glutamine}$ (Millipore)) to form the embryonic bodies (EBs) on day1. On day 2, EBs were added with RA (Retinoic acid, SigmaAldrich) and SAG (Smoothened agonist, Cayman Chemical), a Shh pathway activator [44] and cultured for another 2 to 3 days to promote MN differentiation. On day 5 , cells expressing GFP under the control of spinal cord motor neuron-specific promoter $\mathrm{Hb} 9$, i.e. $\mathrm{MN}$, would appear, and the EBs were dissociated with 0.25\% Trypsin-EDTA (Gibco), plated on coverslips pre-coated with $0.01 \%$ poly-D-lysine (Sigma)/ 0.01\% ornithine (Invitrogen), $5 \mu \mathrm{g} / \mathrm{ml}$ laminin (Invitrogen), and cultured in the MN medium (45\% Advanced DMEM/F12, 45\% Neurobasal, 10\%l Knockout-SR, 2 mM Lglutamine, 1x B27 (Gibico), 1x N2 supplement (Gibico), 10 $\mathrm{ng} / \mathrm{ml}$ GDNF (Peprotech). When required, GFP (+) MNs were purified by flow-sorting in FACSAriaII SORP. 


\section{Cell lines}

Neuro 2a (N2a) cells were cultured in minimum essential medium (MEM, Gibico) supplemented with 10\% FBS (Gibico), 1\% sodium pyruvate (Invitrogen), 10\% FBS (Gibico) and 1\% antibiotics (100 IU/mL penicillin and $100 \mathrm{~g} /$ $\mathrm{mL}$ streptomycin, Invitrogen), whereas HEK293T cells was cultured in Dulbecco's modified Eagle's medium (DMEM, Gibico) supplemented with 10\% FBS and 1\% antibiotics.

\section{Behavior tests}

\section{Accelerating rotarod}

Mice were trained for 3 days and tested following the procedures described in Mandillo et al. (2008). In brief, the mice were placed on a rod (Ugo Basile Rota-Rod 47, 600 ) rotating at $4 \mathrm{rpm}$ constant speed. In testing phase, the rotation speed was accelerated from 4 to $40 \mathrm{rpm}$ in $5 \mathrm{~min}$. Latency and fall-off rpm of each mouse was recorded when the mice fell from the rod.

\section{Hindlimb-clasping test}

The test was carried out as described previously [30]. The mice were suspended by grasping their tails and their hindlimbs position were observed for $10 \mathrm{~s}$. The normal mice consistently kept their hindlimbs away from the abdomen. Hindlimbs of the knock-in mice having motor dysfunction would be retracted toward or touching the abdomen during the suspended time.

\section{T-maze test}

T-maze apparatus was used to measure spatial working memory following the procedures described by Deacon and Rawlins (2006) [21] and Shoji et al., (2012) [59]. In brief, the mice were in food restriction $(3 \mathrm{~g} \pm 0.5 \mathrm{~g} /$ mouse/day) and treated with the reward pellets $(40 \mathrm{mg} /$ mouse/day) for 3-4 days before the test. They then stayed in the maze for habituation for at least $5 \mathrm{~min}$ and repeat 5 times until they were accustomed to reward pellets before the test. Mice were tested on 2 trials in this test including sample phase (learning and memory phase) and choice phase (reversal learning phase) as shown in Additional file 2: Figure S2a. Each trial is repeated five times a day and continued until the mice can get over $80 \%$ correction for 3 -month old $+/+$ mice, and over $60 \%$ correction for the 24 -month old $+/+$ mice. The standby site of young mice is $30-35 \mathrm{~cm}$ from the $\mathrm{T}$ intersection; the old N390D/+ mice were $10 \mathrm{~cm}$ from the $\mathrm{T}$ intersection because they would have movement problem. Between each run, the apparatus was cleaned with $75 \%$ alcohol to remove the effect of olfactory.

\section{Examination of hindlimb skeletal muscles and soleus}

The tricep surae consisting of a pair of gastrocnemius muscle and one soleus muscle is the major muscle of the calf of human and most of mammals. After cutting down the right hind limbs, the diameters of the fresh calf circumference were measured. The standard position of the calf muscle for measurement was the widest circumference of the calf as shown in the carton of Fig. 1d, approximately $1.2 \mathrm{~cm}$ from the calcaneum and parallel to the tibia. The soleus is a powerful muscle involved in standing and movement. After isolation from the left calf muscles, the soleus was weighted by electronic micro balance. The right calf and left soleus were also immersed in 4\% PFA overnight (post-fixation) for further analysis.

\section{NMJ staining}

The NMJ staining was carried out as the methods described by Tremblay et al., [62]. The fixed soleus muscle samples were teased apart to fibers by using forceps, and the soleus muscle fibers were permeabilized with $10 \%$ FBS, $1 \%$ TritonX100 diluted in PBS for $1 \mathrm{~h}$ at room temperature. The axons and nerve terminals of NMJ were labeled with antibodies including anti-SV2A (1:200 dilution; Cell Signaling) and anti-NF (1:200 dilution; Proteintech) for $72 \mathrm{~h}$ at $4{ }^{\circ} \mathrm{C}$, incubated with the secondary antibody Alexa Fluor 488 for $48 \mathrm{~h}$ at room temperature, and then incubated with Alexa Fluor 594-conjugated $\alpha$-Bungarotoxin $(\alpha$-BTX; $2.0 \mu \mathrm{g} / \mathrm{ml}$; Thermo Fisher Scientific) for $2 \mathrm{~h}$ at room temperature. The images of $\mathrm{MNJ}$ were acquihired with Z-stacking and projected into 2D images from use of Zeiss LSM 780 Confocal Microscope. The percentage of denervation of the NMJ mentioned in the text was calculated in the formula $\%=\frac{\text { the number of endplates withcpmplete loss of SV2A and NF signals }}{\text { total number of endpaltes with } \alpha-B T X \text { signal }}$. The numbers of soleus NMJ examined in the 3-month old and 6-month old $+/+$ and N390D/+ male mice are indicated in Fig. 2g.

\section{Proteasome chymotrypsin-like activity assay}

The forebrain and spinal cord proteins were extracted freshly. This assay was carried out in 96 well plates with $50 \mu \mathrm{g}$ of the extracts lysate and fluorescently labeled substrate succinyl-Leu-Leu-Val-Tyr-7-amido-4-methylcoumarin (Suc-LLVY-AMC; final conc. Was $100 \mu$ M; BMLP802-0005, Enzo Life Sciences, NY) in assay buffer [20 mM Tris- $\mathrm{HCl}(\mathrm{pH}=7.4), 5 \mathrm{mM} \mathrm{MgCl} 2,5 \mathrm{mM}$ DTT and $2 \mathrm{mM}$ ATP]. The kinetics of the Suc-LLVY-AMC cleavage was measured spectrofluorometrically at $5 \mathrm{~min}$ intervals for $1 \mathrm{~h}$ under $37^{\circ} \mathrm{C}$ by using an EnSpire Multiplate Reader (Ex/ $\mathrm{Em}=360 \mathrm{~nm} / 460 \mathrm{~nm}$; PerkinElmer). Negative control assay was conducted in the presence of the specific proteasomal inhibitors MG-132 (474,790, Calbiochem) and Lactacystin (70,988, Cayman).

\section{Immunofluorescence staining analysis}

For staining of the brain and spinal cord, $14 \mu \mathrm{m}$ thick brain sections and $10 \mu \mathrm{m}$ thick spinal cord sections were 
$\mathbf{a}$

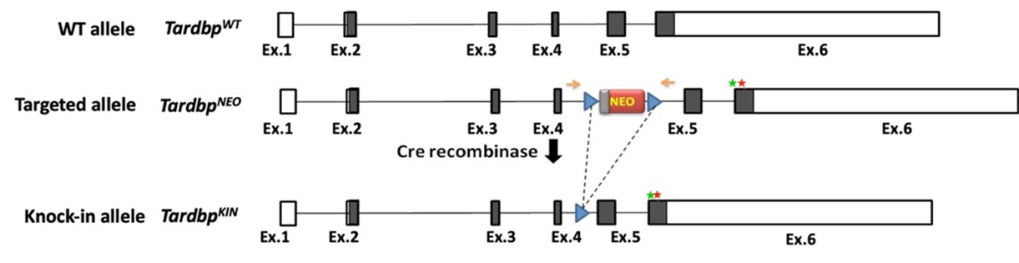

DExon (Ex.); UTR \Coding region $\$ LoxP site NEO Neomycin resistant $\rightarrow$ PCR primer $\star A 315 T \star N 390 D$

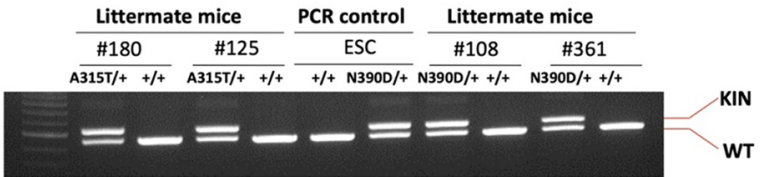

b

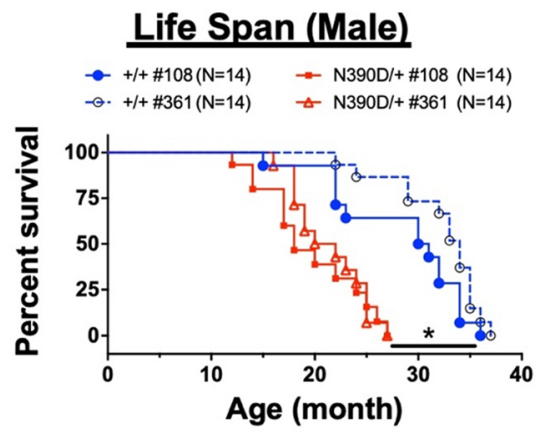

\section{Life Span (Male)}

$\rightarrow$ ๑) $++\# 125(\mathrm{~N}=14) \rightarrow \mathrm{A} 315 \mathrm{~T} /+\# 125(\mathrm{~N}=14)$

$\rightarrow+/+\# 180(\mathrm{~N}=14) \rightarrow \mathrm{A} 315 \mathrm{~T} /+\# 180(\mathrm{~N}=14)$

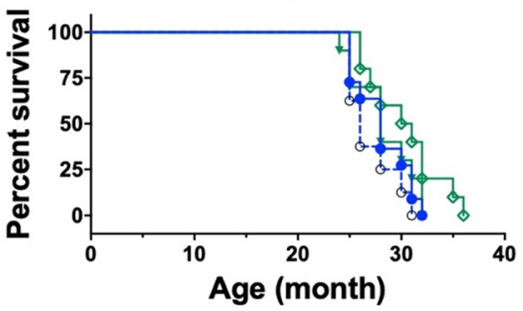

c

\section{Bodv Weight of Remains (Male)}

- $+/+\# 108(\mathrm{~N}=14)=\mathrm{N} 390 \mathrm{D} /+\# 108 \quad(\mathrm{~N}=14)$

○ $+++\# 361(\mathrm{~N}=14)$ 口 $\mathrm{N} 390 \mathrm{D} /+\# 361 \quad(\mathrm{~N}=14)$

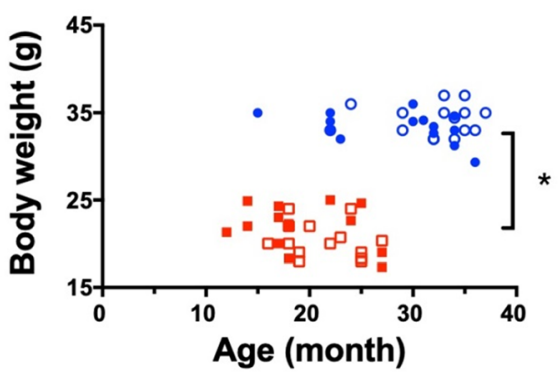

$\square+/+\quad(\mathrm{N}=14 /$ clone group $)$

$\square \mathrm{N} 390 \mathrm{D} /+$ (N=14/clone group)

*

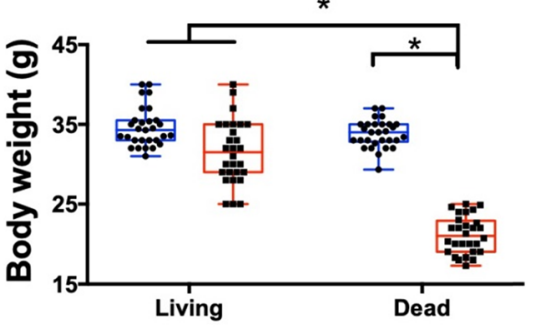

Fig. 1 Age-dependent ALS-like phenotypes of Heterozygous male N390D/+mice. a Schematic diagram of targeted knock-in (KIN) of ALSassociated mutant TDP-43, A315T (green star) and N390D (red star), in mouse Tardbp gene. Both sides of the NEO cassette in the targeted allele $\left(\operatorname{Tardb}^{N E O}\right.$ ) was flanked by lox $P$ sequence (arrowhead). The genotypes of mice carrying the different knock-in allele (Tardbp ${ }^{K I N}$ ) were validated by PCR, as exemplified for two heterozygous lines each for N390D and A315T. \#125 plus \#180 and \#108 plus \#361 are the name of mouse lines of A315T and N390D, respectively. For more details, see Methods. b The survival rates of two lines each of A315T/+ (right panel) and N390D/+ male mice (left panel) are compared to their +/+ littermates. Note the significantly shorter life span of N390D/+ male mice, but not A315T/+ male mice, than the $+/+$ male mice. ${ }^{*} p<0.05$. c Comparison analysis of the average body weight of the remains of N390D/+ male mice to that of the living mice weighed before they died. The left panel shows the comparison of the weight of remains between $+/+$ and N390D/+ male mice in a manner consistent with the survival curve. The right panel shows the comparison of the body weight of the remains of N390D/+ male mice to the body weight recorded when they are still alive. ${ }^{*} p<0.05$. The numbers $(\mathrm{N})$ of mice analyzed per group are listed in the figure 

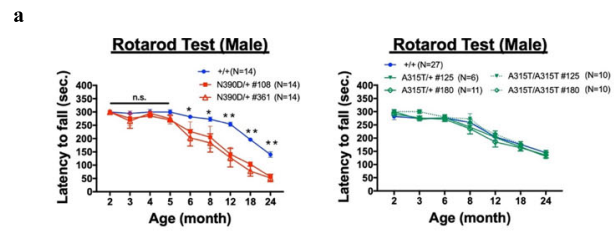

b

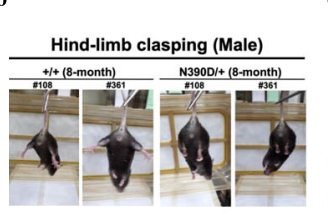

c
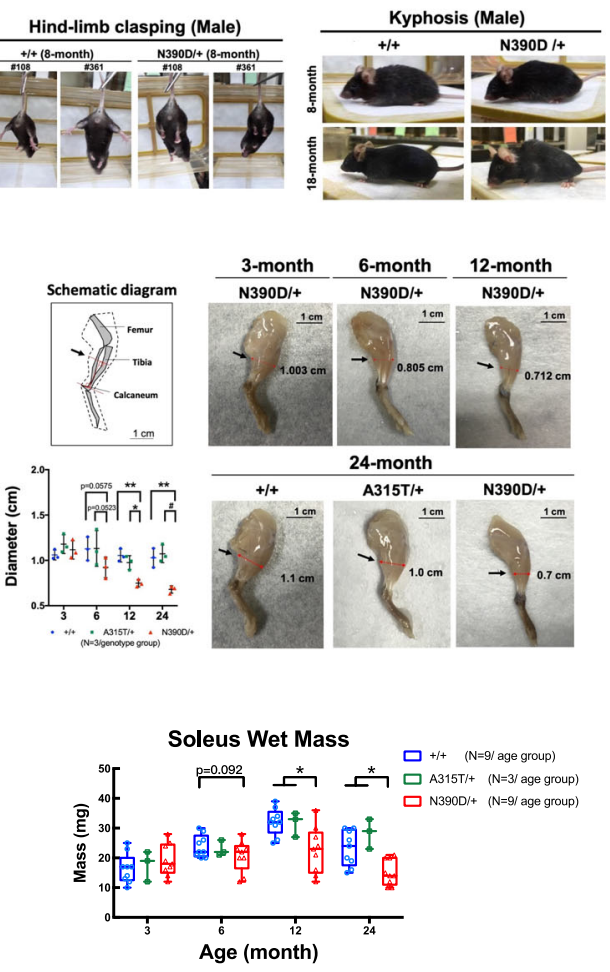

f

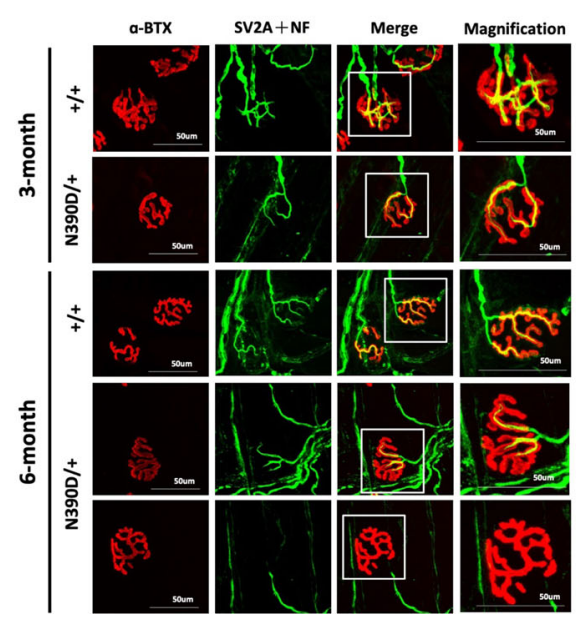

g

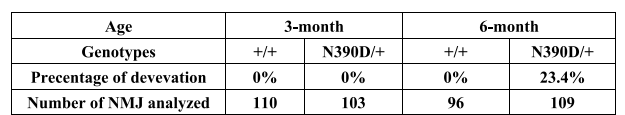

Fig. 2 Age-dependent motor dysfunction and muscle atrophy of heterozygous male N390D/+ mice. a Rotarod test of heterozygous knock-in mouse lines. Both lines of N390D/+ male mice (left panel) exhibited motor dysfunction at the age of 6 months, but not the two A315T/+ mouse lines (right panel). The average time periods of mice staying on the rotarod (mean \pm SEM) at different ages are shown in the line graphs. ${ }^{*} p<0.05 ;{ }^{* *} p<0.01$, n.S., not significant. The numbers (N) of mice analyzed per group are listed in the figure. $\mathbf{b}$ Hind-limb clasping test. Exemplified are the abnormal clasping behavior of 8month old N390D/+ male mice (right 2 panels) and their +/+ littermates (left 2 panels). c ALS-like kyphosis phenotype of N390D/+ male mice (right panels) and the $+/+$ littermates (left panels) at the ages of 8 months and 18 months, respectively. $\mathbf{d}$ Cartoon illustration of the standard measurement position (arrow) of the calf muscle by red I symbol. Photos of the hind-limb muscles of 3-, 6-, 12- and 24-month old N390D/+ male mice, and 24-month old +/+ and A315T/+ male mice, respectively. The statistical results are shown on the lower left side. The red lines point to the measured sites of the muscle. Scale bars $1 \mathrm{~cm}$. ${ }^{*} p<0.05 ;{ }^{* *} p<0.01 ; \# p<0.001$. e The soleus muscles of hind-limb were isolated from +/+, A315T/+ and N390D/+ male mice at different ages. ${ }^{*} p<0.05$. $\mathbf{f}$ The NMJ of soleus from $+/+$ and N390D/+ male mice were analyzed by whole-mount IF staining using $a-$ Bungarotoxin-555 (a-BTX, red) and anti-SV2A (green, a synaptic vesicle marker) plus anti-NF (green, a nerve marker). The white box indicates the magnified region. $\mathrm{N}=3$ (randomly chosen from each of the two independent lines) per group. Scales bars $50 \mu \mathrm{m}$. g The percentages of denervation of NMJs of the soleus muscles of hind-limb at the ages of 3 and 6 months, respectively. The numbers of NMJ analyzed are list in the bottom of the table

prepared as described before [74]. Antibodies for IF staining of these sections included goat anti-choline acetyltransferase (ChAT; 1:800 dilution; Millipore), mouse anti-NeuN (1: 200 dilution; Millipore), rabbit anti-TDP-43 (1:1000 dilution; Proteintech), rabbit anti-pTDP-43 (1:500 dilution; Proteintech), mouse anti-ubiquitin (1:200 dilution; Novus), and rat anti-GFAP (1:200 dilution; Invitrogen).

For staining of ESC-derived $\mathrm{MN}$, the culture medium was removed and the cells were washed gently with PBS. MN on coverslips were fixed by freshly made and pre-colded $4 \%$ paraformaldehyde for $20 \mathrm{~min}$. The samples of spinal cord sections or ESC-derived $\mathrm{MN}$ were then permeabilized with $\mathrm{PBS} / 0.5 \%$ Triton X-100 for $7 \mathrm{~min}$ at room temperature. After blocking with $2 \%$ fetal bovine serum (FBS) for $1 \mathrm{~h}$ at room temperature, the samples were incubated overnight at $4{ }^{\circ} \mathrm{C}$ with one or more of different antibodies, including goat anticholine acetyltransferase (ChAT; Millipore), rabbit anti-TDP43 (Proteintech), and mouse anti-Tau (1:200 dilution; Thermo Pierce). After washing, the samples were incubated with DAPI (Invitrogen) plus Alexa Fluor 488-conjugated, Alexa Fluor 546-conjugated, and Alexa Fluor 647-conjugated secondary antibody (Invitrogen) for $1 \mathrm{~h}$ at room temperature. The images were analyzed on a Zeiss LSM 780 confocal microscope.

\section{Western blotting analysis}

The mouse tissues $(200 \mathrm{mg} / \mathrm{ml})$ were extracted with RIPA buffer $(0.1 \%$ SDS, $1 \%$ Nonidet P- $40,0.5 \%$ sodium 
deoxycholate, $5 \mathrm{mM}$ EDTA, $150 \mathrm{mM} \mathrm{NaCl}, 50 \mathrm{mM}$ Tris$\mathrm{HCl}, \mathrm{pH} 8.0)$ or urea buffer (7 M urea, $2 \mathrm{M}$ thiourea, $4 \%$ CHAPS, $30 \mathrm{mM}$ Tris- $\mathrm{HCl}$, $\mathrm{pH} 8.5)$ containing protease and phosphatase inhibitors (Roche). After homogenization and centrifugation of the tissue at $13,000 \mathrm{rpm} 4{ }^{\circ} \mathrm{C}$ for 30 $\mathrm{min}$, the solution from the urea buffer-derived extract was defined as the "total protein extract", and the supernatant from the RIPA buffer extract(s) was defined as the "soluble fraction". The pellet from the RIPA buffer-derived extract was washed by RIPA buffer for 3 times, dissolved in urea buffer, and defined as the "insoluble fraction". The cellular extracts of cultured MN were prepared in the following way. The cultured spinal MN (see below) were purified by GFP (+)-based sorting in FACSAriaII SORP. The purified GFP (+) MNs were cultures for different days and lysed with lysis buffer. $1^{*} 10^{6} \mathrm{MNs}$ were lysed with either RIPA buffer or urea buffer. For in vitro phosphorylation of TDP-43 as a positive control of Western blotting, the recombinant TDP-43 was expressed in E. coli. and purified through Nickel affinity column. The purified TDP-43 was then prepared in $3 \mu \mathrm{M}$ in $10 \mathrm{mM}$ Tris, $\mathrm{pH}$. 8.0, $5 \mathrm{mM} \mathrm{MgCl} 2,200 \mu \mathrm{M}$ ATP, and $1 \mu \mathrm{l}$ Casein Kinase 1 (New England BioLabs) in $100 \mu$ l solution. The reaction was incubated at $30^{\circ} \mathrm{C}$ for $2 \mathrm{~h}$ and stopped by adding SDS containing sample loading dye.

The different protein extracts were separated by $12-$ 15\% SDS-PAGE and immunoblotted with the appropriate primary antibodies (anti-TDP-43 and anti-pTDP-43 from Proteintech, anti-ubiquitin from Proteintech, antihiston H4 from Millipore, anti-LC3 from NOVUS, antip62 from Proteintech, anti-Bcl-2 from Proteintech, and anti-tubulin as well as anti-actin from Sigma) and then the secondary antibodies. The bound antibodies were detected by using the chemiluminescence Western blotting detection reagent ECL (Amersham Pharmacia Biotech, Piscataway, NJ). The expression levels of different proteins were compared by measuring their band intensities on the blots with Image J software (NIH).

\section{Preparation of nuclear and cytosolic extracts}

The standard process followed that by Arnold et al. (2013). Briefly, spinal cord was lysed gently with $10 \mathrm{x}$ (vol./weight) hypotonic buffer A (10 mM Hepes- $\mathrm{KOH}, \mathrm{pH} 7.4,10 \mathrm{mM}$ $\mathrm{KCl}, 1.5 \mathrm{mM} \mathrm{MgCl}, 0.5 \mathrm{mM}$ EDTA, $0.5 \mathrm{mM}$ EGTA) containing protease inhibitors (Roche) by homogenization. After 15 min on ice, $0.5 \%$ NP- 40 was added and the samples were vortexed and centrifuged at $800 \mathrm{~g}$ for $5 \mathrm{~min}$ at $4{ }^{\circ} \mathrm{C}$. The supernatant was defined as the cytosolic fraction. For preparation of the nuclear extract, the nuclear pellet was washed with hypotonic buffer $\mathrm{A}$, added $5 \mathrm{x}$ (vol/wt) extraction buffer (10 mM Hepes-KOH, pH 7.4, $0.42 \mathrm{M} \mathrm{NaCl}$, $2.5 \%$ (vol/vol) glycerol, $1.5 \mathrm{mM} \mathrm{MgCl}, 0.5 \mathrm{mM}$ EDTA, 0.5 $\mathrm{mM}$ EGTA, $1 \mathrm{mM}$ DTT) containing protease inhibitors, and then incubated at $4 .{ }^{\circ} \mathrm{C}$ while rotating at $60 \mathrm{rpm}$ for 40 min.

\section{Survival rate analysis of cultured $\mathrm{MN}$}

A modified MN induction protocol was used for this analysis. On day 5 of the differentiation phase, the EBs were directly cultured in the MN medium without dissociation by trypsin. The EBs were then examined by FACS (LSRII12P) for 14 days in culture. The percentage of the GFP (+) MN in the EBs on the 1st day was defined as $100 \%$ and the folds of change on the following days were quantitated and compared for the WT and mutant MN.

\section{RT-PCR and RT-qPCR analysis}

Total RNAs from the tissues or cells were isolated following the standard protocol using Trizol reagent (Thermo Fisher Scientific). cDNA synthesis was carried out using SuperScript II reverse transcriptase (Invitrogen) and subjected to PCR. Alternatively, real-time PCR (qPCR) using SYBR Green PCR Master Mix (Applied Biosystems) and ABI 7500 real-time System was carried out. All data were analyzed after normalization to the expression level of the Gapdh gene. The sequences of the PCR primers are listed below:

Tardbp forward primer: 5'- GGTAATCCAGGTGC TTTG-3'

Tardbp reversed primer: $5^{\prime}$ - CCTGCATTTGATGC TGACCC-3'

Bcl-2 splicing forward primer (P1):5' -TTCGGGGAAG GATGGCGCAAGC- 3'

Bcl-2-201 forward primer (P2): 5' - ACGGAGGCTG GGATGCCTTTGTGG-3'

Bcl-2 reversed primer (P3): 5' - TCACTTGTGGCCCA GGTATGC-3'

Eif4h splicing forward primer: AAGCTAGCTATCCA TGGCGGACTTCGACACCTACGACG-3'

Eif4h splicing reversed primer: 5'-CCCGGGAGCT CTCATTCTTGCTCCTTTTGAACGAC-3'

Mapt forward primer: 5'-AGGAAATGACGAGAAG AAAGC-3'

Mapt reversed primer: 5'-GACCCTGGAGGAGTCT TAGG - 3'

Rbm39 forward primer: 5'- GGCCGCTACAGAAG TCCTTACTCC - 3'

Rbm39 reversed primer: 5'-ACCCAATCTTTCCT CGGATGG- 3'

ANkrd12 forward primer: 5' - TTACTATTAGCCCA TCAAGAAATGAAG - 3 '

ANkrd12 reversed primer: 5' - TATGTCCTGGATCT GAATCTGTGTC-3'

Expression plasmid construction and DNA transfection cDNAs of mouse wild type TDP-43, TDP-43 (A315T) and TDP-43 (N390D) with addition of a Myc epitope 
tag to the 3' -end were generated by RT-PCR of different mouse spinal cord RNAs as the templates. The PCR primers used were: forward 5'-CCG CTC GAG CGG ATG TCT GAA TAT ATT CGG GTA AC-3'; reverse 5' - TGC TCT AGA GCA CAT TCC CCA GCC AGA AGA C-3'. These cDNA fragments were first cloned into pGEM-T vector (Promega Corporation) and then subcloned into the $\mathrm{XhoI} / \mathrm{XbaI}$ sites of $\mathrm{pEF}$-myc vector (Promega Corporation). The generation of expression plasmids carrying human wild-type TDP-43, TDP-43 (A315T), and TDP-43 (N390D) cDNA, respectively, was described in Wu et al. [75].

\section{DNA transfection}

The N2a cells were transfected with the pEF-myc vector or different mouse TDP-43 expression plasmids. HEK293T cells were transfected with the vector or different human TDP-43 expression plasmids [75]. DNA transfection was carried out with Lipofectamine 2000 (Invitrogen) according to the manufacturer's protocol. The amount of the plasmid DNA used in each transfection was $4 \mu \mathrm{g}$ per $6-\mathrm{cm}$ dish. The cells were harvested at $24 \mathrm{~h}$ post-transfection and analyzed by different assays, e.g. Western blotting, calcium imaging, etc.

\section{Cyclohexamide chase assay}

The procedures followed those by Huang et al. (2014) In brief, MNs on day 2 were treated with cycloheximide $(20 \mathrm{mg} / \mathrm{ml})$ for different time periods $(2,4,8,12$ and 24 h). The levels of TDP-43 in the treated MN were analyzed by Western blotting and the relative intensities of the TDP-43 bands were quantified by AlphaEaseFC software.

\section{Calcium imaging}

MNs were dissociated on differentiation day 5 , plated on coated $22 \times 22 \mathrm{~mm}$ glass coverslips, and grown in $\mathrm{MN}$ medium until calcium imaging experiments. HEK293T cells were cultured on $0.1 \%$ gelatin-coated 22 X $22 \mathrm{~mm}$ glass coverslips and transfected with plasmid DNAs for $24 \mathrm{~h}$ before calcium imaging. Before calcium imaging, the MNs were treated with 2uM Fura-2-AM (Invitrogen) in HBSS (Invitrogen) containing $2 \mathrm{mM} \mathrm{CaCl}_{2}$ in the dark chamber and incubated at $37^{\circ} \mathrm{C}, 5 \% \mathrm{CO}_{2}$ for $45 \mathrm{~min}$. The excess Fura-2-AM was washed out with HBSS (without $\mathrm{CaCl}_{2}$ ) and incubated for an additional $30 \mathrm{~min}$ in HBSS (containing $2 \mathrm{mM} \mathrm{CaCl}_{2}$ ) for recovering, and then the coverslips were transferred onto the recording chamber of an inverted fluorescence microscope (Zeiss Axiovert 200) equipped with a $20 \mathrm{X}$ objective lens and MetaFluor (Molecular Devices) acquisition and analysis software. The fluorescence signals at $510 \mathrm{~nm}$ were acquired every $2 \mathrm{~s}$ in $5 \mathrm{~min}$ by UV excitation at wavelengths of $340 \mathrm{~nm}$ (indicating calcium ion-bound- Fura-2-AM) and $380 \mathrm{~nm}$ (indicating calcium ion-free-Fura-2-AM), respectively. The formula $R=\frac{\Delta 340}{\Delta 380}$, in which the $\Delta$ indicated the values of $340 \mathrm{~nm}$ or $380 \mathrm{~nm}$ minus their background values, was used to calculate and compare the relative levels of intracellular calcium ion of different types of $\mathrm{MN}$ in culture.

\section{Statistical analysis}

Statistical differences were analyzed by Kaplan-Meier and log rank test(s) for the survival rates, two-way ANOVA and Bonferroni post hoc analysis for multiple group comparisons, and the unpaired Student's t-test for two group comparisons (SPSS version 15.0, SPSS Inc. and Prism (version 7, GraphPad software). The error bars of mouse behavior were showed by SEM, and the error bars of molecule and cellular analysis were displayed by SD.

\section{Data collection}

The images of immunofluorescence staining were acquired with Z-stacked on a Zeiss LSM 510 META confocal microscope software; basically, one slide contain 3 spinal cord sections or 2 brain sections of one mouse at least; each sample of IF staining will duplicate; the merge images and analysis such as motor neuron number and axonal length were measured/calculated via ImageJ $(\mathrm{NIH})$. The bands intensities of RT-PCR and Western blotting were also quantified through ImageJ or AlphaEaseFC 4.0 (Alpha Innotech) or ImageJ $(\mathrm{NIH})$. The raw data of Calcium imaging is recorded via MetaFluor (Molecular Devices) acquisition and analysis software, and the result were calculated using Prism 7.

\section{Results}

An ALS-like phenotype of mice bearing a single TDP-43 N390D mutation, but not an A315T mutation

We generated mouse lines bearing homologous knockin of human ALS-associated base substitutions, A315T and N390D, respectively. The TDP-43 A315T was identified in all affected members but not the healthy control subjects of several European families [27, 33], while N390D was identified in a sporadic ALS-TDP patient from Quebec [33]. We substituted the conserved nucleotide $\mathrm{G}$ at position 943 with $\mathrm{A}$ (for A315T) or A at position 1168 with G (for N390D) in the mouse tardbp gene (Fig. 1a). Although the ALS-TDP patients carried A315T or N390D mutation on only one allele [27, 33], we did try to obtain homozygous offspring for analysis by intercrossing the heterozygous knock-in mice. Either $\mathrm{A} 315 \mathrm{~T} /+$ or $\mathrm{N} 390 \mathrm{D} /+$ mice were fertile and the male mice have normal courtship behavior. However, in contrast to homozygous A315T/A315T mice, no homozygous N390D/N390D mice could survive to the age of 3 weeks. In parallel, most of the dead newborn pups were 
genotyped as N390D/N390D and the rest were N390D/ + (see Additional file 1: Figure S1a). Notwithstanding, the amount of TDP-43 protein in the spinal cord of homozygous N390D/N390D mice was significantly higher than the wildtype mice (Additional file 1: Figure S1c). Therefore, the death cause of N390D/N390D pups could result from a lethal effect of the homozygous N390D/N390D mutation on early development of the mice, as also observed for the homozygous human TDP43 A315T knock-in mouse model generated by Stribl's group [61]. In addition, the male-to-female ratio of the survived N390D/+ pups was 1 to 2.6 approximately (Additional file 1: Figure S1b). Notably, the disease-onset ages of individual N390D/+ female mice were highly variable as reflected by the rotarod test, and the survival time of $\mathrm{N} 390 \mathrm{D} /+$ female mice was significantly longer than males (Additional file 1: Figure S1d), with average age being $25.5 \pm 6$ months. Around $30 \%$ of the N390D/+ female mice were indistinguishable from the $+/+$ female mice suggesting that estrogen might exert a protective effect $[20,47,50]$. Based on the above, we concentrated on the use of the N390D/+ male mice for all analysis depicted in the following. Although the cause(s) for their eventual death was unknown, the N390D/+ male mice derived from 2 independent ESC lines (\#108 and \#361) displayed a shorter life span than either +/+ or A315T/+ male mice, with average age of $19.5 \pm 2$ months (Fig. 1b). Like the heterozygous Q331K/+ mice studied by White et al., [72] the N390D/+ male mice from either line had similar body weight as the $+/+$ male mice (Additional file 1: Figure S1e) although conspicuous weight loss was observed in their remains (Fig. 1c), possibly in part resulted from the lack of nutrition at the end stage of their lives. These data indicate that loss of body weight was not the initial pathological evens of ALS in $\mathrm{N} 390 \mathrm{D} /+$ male mice.

Rotarod and T-maze tests were used to assess whether the knock-in mice would develop ALS- and/or FTLD-like phenotypes. Surprisingly, while heterozygous N390D/+ male mice from either line \#108 or \#361 exhibited significant motor dysfunction at the ages of 6 months and older, heterozygous and homozygous A315T male mice appeared indistinguishable from $+/+$ littermates (Fig. 2a). Notwithstanding, the young as well as old N390D/+ male mice did not develop impaired performance in the T-maze task, as shown in Additional file 2: Figure S2a. Furthermore, there was no loss of neurons in the dentate gyrus (DG), CA1 and CA3 regions of hippocampus of N390D/+ male mice in comparison to the $+/+$ male mice (see Additional file 2: Figure S2b). Over time, the N390D/+ male mice from either line \#108 or \#361 started to show abnormal hind limb-clasping and kyphosis at around 8 months of age, as exemplified in Fig. $2 \mathrm{~b}$ and $\mathrm{c}$, and displayed spastic and trembled gait at 18 months and beyond (Additional file 9:
Movie S1 and Additional file 10: Movie S2), comparing to age-matched +/+ mice (Additional file 11: Movie S3). Since the paralysis happened in the hindlimb of N390D/+ mice, we guessed that the hindlimbs were affected earlier than the forelimbs. Also, we analyzed mainly the soleus muscle, which was one of the main muscles that control walking, running and jumping, following the study by Tremblay et al. [62] on the denervation of neuromuscular junctions in SOD-1 mice. In contrast to young N390D/+ male mice, the 12-month and 24-month old N390D/+ male mice exhibited significant skeletal muscle atrophy when compared to $+/+$ or $\mathrm{A} 315 \mathrm{~T} /+$ mice, as represented by decrease of the wet weight of soleus muscle and reduction of the calf muscle volume (Fig. $2 \mathrm{~d}$ and e). Wet mass was a relatively simple and preparatory sign for muscle atrophy as also used by others, eg. Goto et al., [28], Dang et al., [19], etc. Furthermore, while the innervation of neuromuscular junctions (NMJ) in the soleus muscle of 3-month old N390D/+ mice appeared to be normal as the $+/+$ mice (yellow color, Fig. 2f), denervation of the NMJ of soleus muscle was detected in N390D/+ mice at the age of 6 months, as exemplified in the representative images of the bottom panel in Fig. 2 f, by approximately $23 \%$ in comparison to the $+/+$ male mice (Fig. 2g). The extent of NMJ denervation progressively increased with further aging of the N390D/+ mice (data not shown). Based on the similarities of N390D/ + male mice derived from lines \#108 and \#361 with respect to their survival curves, body weight changes and rotarod test result, we mixed used mice from the two lines for the following molecular and cellular pathology analysis. The same strategy was applied to the analysis of $\mathrm{A} 315 \mathrm{~T} /+$ and $+/+$ mice.

Molecular and cellular pathology of the TDP-43 (N390D/+) male mice

Accumulation, enhanced cleavage, elevated phosphorylation and increased insolubility of spinal cord TDP-43

Changes in a range of molecular and cellular characteristics were associated with the ALS-like phenotypes of the N390D/+ male mice described above. First, in contrast to A315T/+ male mice, the expression level of TDP-43 protein was elevated in the spinal cord, but not in other tissues, of N390D/+ male mice, and progressively elevated with age in the spinal cord, e.g. newborn, 3, 6, 12 and 24 months (Fig. 3a and b, Fig. $4 \mathrm{~b}$ and Additional file 4: Figure S4a), despite the similar levels of tardbp mRNA (see Additional file 3: Figure S3, a and b). Second, there was an age-dependent enhancement of cleavage of TDP-43 to generate $35-\mathrm{kDa}$ and $25-\mathrm{kDa}$ fragments in the spinal cord of post-symptomatic N390D/+ mice (Fig. 3b), which was characteristic of the spinal cord of ALS-TDP patients $[49,56]$. The enhanced cleavage of TDP43 was accompanied by significantly increased fraction of insoluble TDP-43/ TDP-35/ TDP-25 in the cellular extracts 

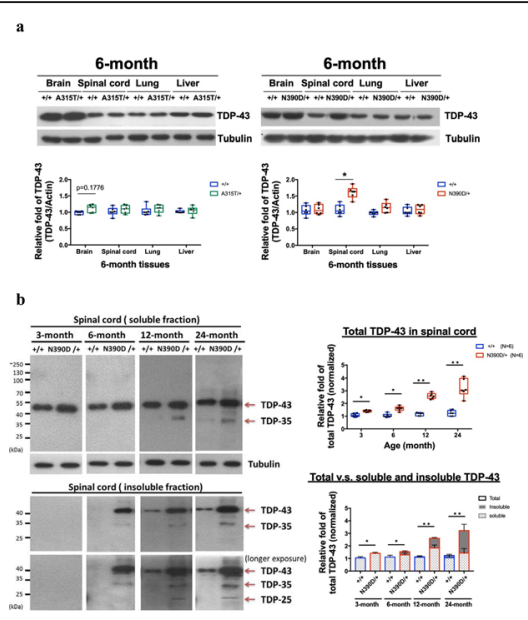

c
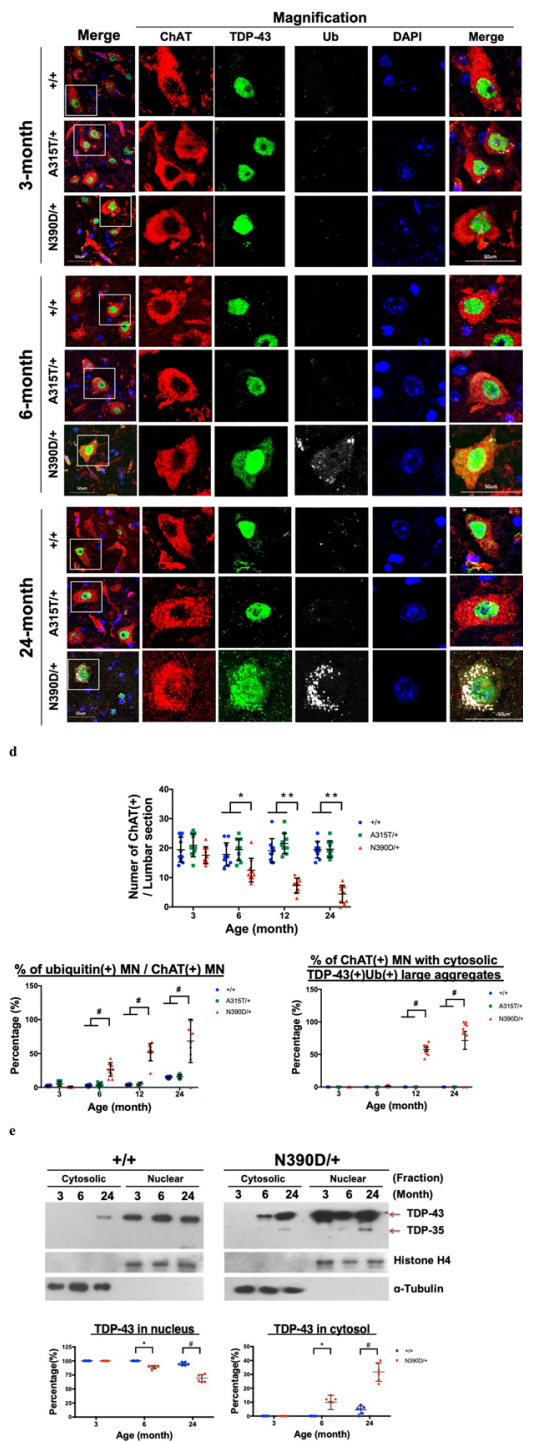

Fig. 3 Patho-signature analysis of TDP-43 in spinal cord of N390D/+ knock-in male mice. a Expression of TDP-43 in different tissues of 6month old A315T/+ (left panel) and N390D/+ male mice (right panel). Statistical analysis is shown in the box plots (min to max with all points). $\mathbf{b}$ Expression of TDP-43 (including TDP-35 and TDP-25) in the soluble and insoluble fractions of spinal cord. The relative fold of total spinal cord TDP-43 is exemplified in the right upper box plots (with all points). The lower stacked bar plot (mean \pm SD) indicates the proportions of soluble and insoluble TDP-43 in the spinal cord of $+/+$ and N390D/+ male mice. c Immunofluorescence co-staining of spinal cord lumbar sections from +/+ and N390D/+ male mice using anti-TDP-43 (green), anti-ubiquitin (Ub, gray) and anti-ChAT (red; a motor neuron marker). DAPI (blue) indicates the locations of the nuclei. Image of the motor neurons are magnified from the ventral horn of the spinal cord. The vessel-like signals are likely due to staining of axons of the motor neurons. The white line boxes in the first column indicate the magnified regions of panels on the right. The scale bars are $50 \mu \mathrm{m}$. d Statistical comparison of the ChAT $(+)$ motor neuron numbers per section, the \% of ubiquitin $(+) \mathrm{MN}$ among the ChAT (+) MN, and the \% of ChAT (+) MN with large ubiquitin (+) TDP-43 (+) MN aggregates. e The cytosolic and nuclear distribution of spinal cord TDP-43 in the N390D/+ and +/+ male mice at different ages. Histone $\mathrm{H} 4$ (nuclear marker) and a-tubulin (cytosolic marker) were used to validate the fractionation of cellular extracts. The scatter plot (mean \pm SD) deduced from the Western blotting data are shown below the blots. $N=6$ (3 mice from each of the two independent lines) per group in $\mathbf{a}, \mathbf{b}$ and $\mathbf{e}$. $\mathrm{N} \geqq 3$ (randomly chosen from each of the two independent lines) per group in $\mathbf{c}$ and d. Significantly different represented in a-e: ${ }^{*} p<0.05$,

${ }^{* *} p<0.01, \# p<0.001$

from mouse spinal cords of N390D/+ male mice at the age of 6 months and beyond (Fig. $3 \mathrm{~b}$ and Additional file 3 : Figure S3c). Thirdly, the amount of the phosphorylated TDP-43 (pTDP-43), which was identified as a component of the ubiquitin-positive inclusions (UPIs) in diseased neurons of ALS and FTLD [48], was increased significantly in the spinal cord (see Additional file 4: Figure S4a), but not the forebrain (see Additional file 4: Figure S4b), of mice at the age of 12 months and beyond.

\section{Age-dependent mislocalization of TDP-43 and pTDP-43, accumulation of ubiquitinated proteins in spinal cord MN, and loss of spinal cord MN}

A characteristic of ALS pathogenesis is the formation of large cytosolic TDP-43(+), ubiquitin(+) aggregates, and depletion of nuclear TDP-43 in diseased motor neurons [48]. The pathogenic significance of these aggregates with regard to the initiation and/or progression of the diseases is not well understood. A whole spectrum of age-dependent pathological features of TDP-43 developed in the motor neurons of the ventral horn in the spinal cord of the male N390D/+ mice was also identified by immunofluorescence (IF) staining (Fig. 3c and d). Since the neurons in the dorsal horn were not motor neurons, we did not focus our analysis on the dorsal horn of the spinal cord. First, anti-ChAT of the spinal cord sections showed that there was an age-dependent 
loss of spinal cord MN in N390D/+ mice. When compared to the $+/+$ and $\mathrm{A} 315 \mathrm{~T} /+$ mice, the loss was nearly $30 \%$ at the age of 6 months, and it increased to $62 \%$ at 12 months and $77 \%$ at 24 months of age (upper scatter dot plot in Fig. 3d). Second, the level ubiquitinated proteins increased in the ChAT $(+) \mathrm{MN}$ of spinal cord of 6month and older, e.g. 24-month old, mice, and most of which were in the cytosol (Fig. 3c, left lower scatter dot plot in Fig. 3d and Additional file 4: Figure S4c). Thirdly, a portion of the TDP-43 was mislocalized to the cytosol in the spinal cord ChAT(+) MN of 6-month old N390D/ + mice without forming large aggregates (diameter $>$ $2 \mu \mathrm{m})$ (Fig. 3c). Larger TDP-43(+) aggregates appeared in the cytosol of spinal cord MN of the older (12-month and 24-month of age) N390D/+ mice, and they were colocalized with the ubiquitinated proteins (Fig. $3 \mathrm{c}$ and right lower scatter dot plot in Fig. 3d). Use of different primary antibodies for immunostaining of different samples generated different patterns of aggregate formation, thus excluding the possibility of the presence of signals from auto-fluorescence of lipofuscin. The IF data were supported by Western blotting analysis of fractionated spinal cord extracts. As shown, the fraction of the cytosolic TDP-43 of spinal cord was $\sim 15 \%$ at the age of 6 months and it increased to $\sim 40 \%$ by 24 months (Fig. 3e). Furthermore, IF staining of the spinal cord sections showed that there was an age-dependent increase of pTDP-43 in the spinal cord (Additional file 4: Figure S4c) and spinal cord MN (Additional file 4: Figure S4d-g) of N390D/+ male mice. Note that there were also strong signals of $\mathrm{Ub}$ and pTDP-43 in the dorsal horn of the spinal cord. Finally, pTDP-43 was also colocalized with ubiquitin partially in the spinal cord MN of 12-month old male N390D/+ mice and this colocalization increased greatly at the age of 24 months (Additional file 4: Figure S4 $\mathrm{f}$ and $\mathrm{g}$ ).

Increasing evidence showed that glial pathology would mediate the disease progression of ALS via reactive astrocytes and microglial activation [52]. In particular, studies of the reactive astrocytes surrounding the degenerating motor neurons in the spinal cord of ALS suggested a crucial role of astrogliosis in ALS pathology [52]. Unlike most of ALS transgenic mouse models displaying strong signal of GFAP in the mouse spinal cord or cortex sections at early stage of pathogenesis refs in review [64], astrogliosis and microgliosis were not seen in the spinal cord sections of 6-month old N390D/+ mice. However, significant astrogliosis was detected in the spinal cord of aged N390D/+ mice (Additional file 5: Figure S5), suggesting the existence of a threshold effect so that the gliosis was moderate in the young N390D/+ male mice.

Where ALS disease begins has remained argumentative. One of the hypotheses is "dying-back", in which ALS begins within the lower motor neurons (LMN) and then the pathology spreads from LMN to the upper motor neurons (UMN) [15, 17, 66]. Notably, in our study, while there was already $30 \%$ loss of motor neurons in the lumbar region of the spinal cord of N390D/+ male mice at the age of 6 months (Fig. 3d), the motor cortex, especially the primary motor cortex, only exhibited significant loss of $\mathrm{NeuN}(+)$ neurons at the age of 24 months old but not 3 months and 6 months (Additional file 4: Figure $\mathrm{S} 4 \mathrm{~h}$ ). This pattern of pathogenesis appeared to be similar to the "dying-back" hypothesis.

\section{Alteration of autophagy and proteasome activity}

The above data clearly revealed abnormal intracellular localization and aggregation of TDP-43 in the spinal cord of the N390D/+ mice in concert with the misregulation of TDP-43 metabolism. The occurrence of TDP-43 protein aggregates was known to be countered by the combined actions of autophagy and the ubiquitin proteasome system (UPS) [57]. We therefore examined the expression patterns of autophagy proteins and the activities of proteasome in the forebrain and the spinal cord. As shown in Fig. 4a, while the ratio of LC3-II/ LC3-I in the spinal cord of 3-month old N390D/+ mice was higher than that of $\mathrm{A} 315 \mathrm{~T} /+$ or $+/+$ mice, it decreased during the post-symptomatic stage to a level significantly lower than those observed in the 6-month old $\mathrm{A} 315 \mathrm{~T} /+$ and $+/+$ mice. In addition, the amount of the classical receptor p62 of autophagy also decreased in the spinal cord, but not the forebrain, of 12-month and 24-month old N390D/+ male mice (Additional file 6: Figure S6, $a$ and b). The proteasome activities in the spinal cord, but not the forebrain, of symptomatic (6and 24-month old) N390D/+ mice were enhanced when compared to the age-matched $+/+$ mice and 3-month old N390D/+ mice (Additional file 6: Figure S6, c and d). The data described above together demonstrate the presence of TDP-43 dependent pathology of the autophagy system in the spinal cord of the symptomatic N390D/ + mice.

\section{Increase of spinal cord $\mathrm{BCl}-2$ protein as a consequence of mis-regulation of $B \mathrm{Cl}-2$ pre-mRNA splicing in N390D/+ male mice}

Among the regulators of the autophagy pathway is the Bcl-2/Beclin-1 complex [43] and Bcl-2 has been reported it involves in neuron survival [51]. Significantly, while there was no difference between the levels of spinal cord $\mathrm{Bcl}-2$ protein among the newborn of $+/+, \mathrm{A} 315 \mathrm{~T} /+$ and $\mathrm{N} 390 \mathrm{D} /+$ male mice, the amount of spinal Bcl-2 of $\mathrm{N} 390 \mathrm{D} /+$ mice was higher than that of the $+/+$ or A315T/+ mice by approximately $1.5,2$, and 4 -fold at the ages of 3,6 , and 12 months, respectively, in parallel to the increase of the spinal TDP-43 protein (Fig. 4b and c, Additional file 7: Figure S7a). Bcl-2 mRNA is one of the 
a

\section{3-month 6-month}

+/+ A315T/+ N390D/++/+ A315T/+ N390D/+ $== \pm= \pm=$ LC3-II - - Tubulin

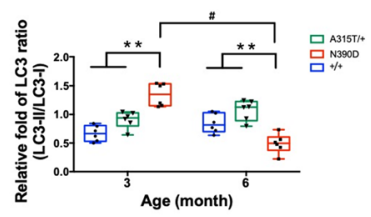

b

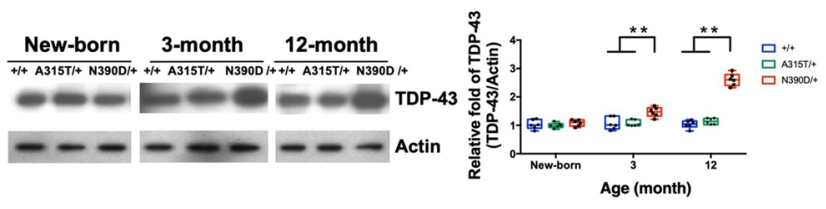

c

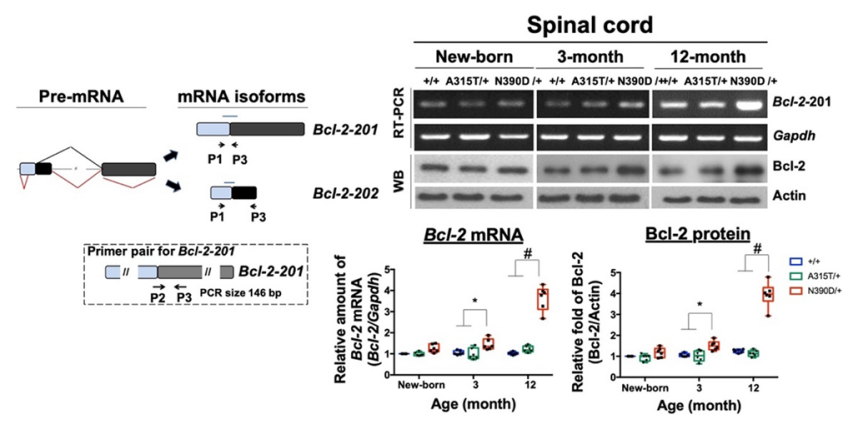

d
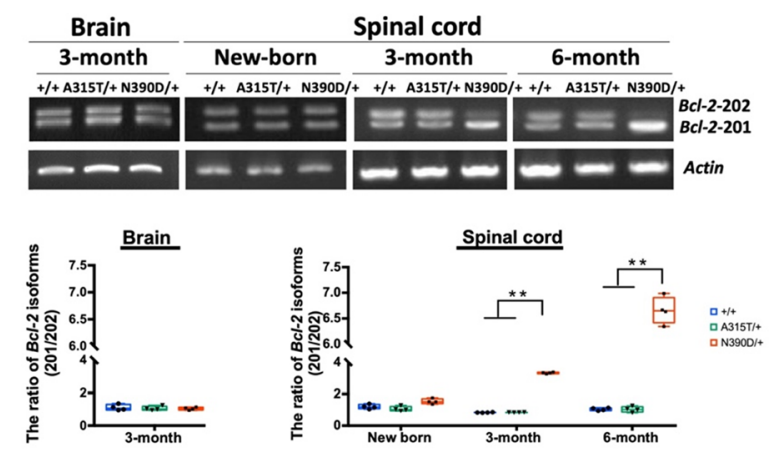

e

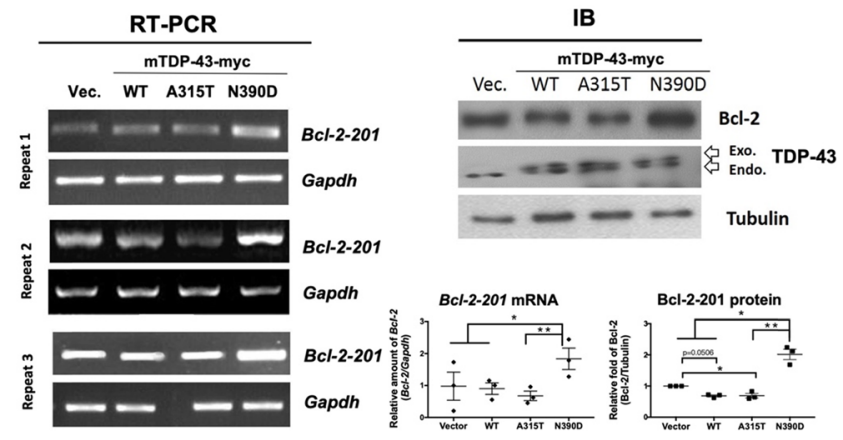

Fig. 4 (See legend on next page.) 
(See figure on previous page.)

Fig. 4 Effects of TDP-43 (N390D) mutation on autophagy and BCl-2 expression. a-b Expression of LC3-I and LC3-II (a) and TDP-43 protein (b) in the spinal cord of $+/+$, A315T/ + and N390D/+ male mice at different ages. The blots are exemplified on the left, and the statistical analyses are shown on the right box plot (min to max with all points). $\mathbf{c}$ The left scheme is the alternative splicing of $B C-2$ pre-mRNA to generate the $B C l-2-$ 201 mRNA (the black lines) and BCl-2-202 mRNA (the red lines). The 3 arrows (P1, P2 and P3) indicate the primers used for RT-PCR. Blue lines indicate location of the coding region. The boxes with different colors are the different exons. The arrows in the dashed frame are the primers (P2, P3) used for detecting the BCl-2-201 mRNA. The expression of BCl-2-201 mRNA and Bcl-2 protein in the spinal cords of A315T/+, N390D/+ and $+/+$ male mice at different ages are exemplified in the upper right two panels, with the statistical analysis of the levels of $B C-2$ mRNA and BCl-2 protein shown in the lower right two box plots (min to max with all points). $\mathbf{d}$ The changes of the relative ratio of the two $B c l-2$ mRNA isoforms. $N=4$ (2 from each of the two independent lines) per group. e Comparison of the levels of Bcl-2 expression in transfected N2a cells. The levels of BCl-2-201 mRNA and BCl-2 protein were assayed by RT-PCR (left panels) and by Western blotting (right upper panel), respectively. The statistical analysis of the levels of $\mathrm{BCl}-2 \mathrm{mRNA}$ and $\mathrm{BCl}-2$ protein are in the right lower 2 dot plots (mean \pm SD). $N=6$ ( 3 from each of the two independent lines) per group in a and c. Significantly different represented in a-e: ${ }^{*} p<0.05,{ }^{* *} p<0.01, \# p<0.001$

potential neuronal RNA targets of TDP-43 [58], we thus suspected that the higher levels of Bcl-2 protein in the $\mathrm{N} 390 \mathrm{D} /+$ spinal cord might be at least in part due to mis-regulation of $B c l-2$ pre-mRNA splicing. Mouse $B c l-2$ mRNA consists of 2 splicing variants, $\mathrm{Bcl}-2-201$ and $\mathrm{Bcl}$ 2-202 (Ensembl), the former of which encodes the wellstudied Bcl-2 protein (NP_033871 from NCBI). Indeed, there was an excellent correlation between the agedependent increase of spinal Bcl-2 protein and that of the functional $\mathrm{Bcl}-2 \mathrm{mRNA}$, i.e. the isoform 201 in the N390D/+ mice, as shown by RT-PCR analysis (Fig. 4d). The ratio of the $\mathrm{Bcl}-2 \mathrm{mRNA}$ isoforms was quantitated using primer 1 and primer 3 in RT-PCR analysis. The data of Fig. $4 \mathrm{c}$ and $\mathrm{d}$ strongly suggest that the increase of $\mathrm{Bcl}-2$ mRNA 201 results from mis-regulation of $\mathrm{Bcl}-2$ alternative pre-mRNA splicing in the spinal cord of $\mathrm{N} 390 \mathrm{D} /+$ male mice.

To investigate the possibility that the increase of TDP-43 (N390D) plays a causative role in altering the alternative splicing of $\mathrm{Bcl}-2$ pre-mRNA towards the generation of higher level of Bcl-2-201 mRNA, we carried out DNA transfection analysis in mouse Neuro-2a (N2a) cell culture (Fig. 4e). As seen, under the condition of equal amounts of the endogenous TDP-43 vs. exogenously overexpressed mouse wild-type TDP-43, TDP-43 (A315T) and TDP-43 (N390D), respectively, i.e. increase of the total TDP-43 amount in N2a cells by 2 fold, similar to the range of increases (1.5-2.5 fold) of TDP-43 in the spinal cord of 3month old and 12-month old N390D/+ male mice (Fig. 3b), the endogenous $\mathrm{Bcl}-2$ mRNA 201 and $\mathrm{Bcl}-2$ protein were elevated only in N2a cells expressing the exogenous TDP43 (N390D) (Fig. 4e). Taken together, the data from Fig. 4b-e demonstrate that at comparably high levels, only mutant TDP-43 (N390D), but not wild-type or mutant TDP-43 (A315T), increases the expression of Bcl-2 mRNA isoform 201 as the result of changes in alternative splicing of the $B c l-2$ pre-mRNA.

Besides $B c l-2$, we also checked the expression patterns of several known TDP-43 target genes. Among them, the splicing pattern of the pre-mRNA of Eif4h was altered in mutant TDP-43 transgenic mouse models $[1,3,65]$. We found that the alternative splicing scheme of Eif4h pre-mRNA was also mis-regulated in the spinal cord of N390D/+ male mice at the age of 3 months (Additional file 7: Figure S7b) and at the symptomatic stage (data not shown). In addition, similar to changes observed in sporadic ALS patients [55], the mRNA levels of 3 genes, Ankrd12, Mapt, and Rbm39, were decreased in the spinal cord of 3-month old N390D/+ male mice (Additional file 7: Figure S7c) as well as 6-month old ones (data not shown).

\section{TDP-43 proteinopathies and MN degeneration in culture}

To examine whether the differential effects of TDP-43 (N390D and A315T) knock-ins on ALS pathogenesis were due, at least in part, to cell-autonomous effects on spinal cord motor neurons (MN), we generated spinal cord MN in culture. To accomplish this, the N390D/+ and $\mathrm{A} 315 \mathrm{~T} /+$ mice were crossed with Hb9:GFP transgenic mice. Embryonic stem cells (ESCs) were derived from TDP-43 (A315T/+)/ Hb9:GFP or TDP-43 (N390D/ $+) /$ Hb9:GFP mice, and then differentiated to GFP(+) MN in culture (Additional file 8: Figure S8). The survival curves as well as the average axonal lengths of the mutant $\mathrm{MN}$ were similar to those of $(+/+) \mathrm{MN}$ up to 7 days in culture (Fig. 5a-c); however, on day 14 in culture, the survival and average axon length of $(\mathrm{N} 390 \mathrm{D} /+) \mathrm{MN}$ was significantly reduced in comparison to $(+/+) \mathrm{MN}$ or (A315T/+) MN (Fig. 5a-C). Similar to $(+/+)$ MN, the majority of TDP-43 of the mutant MN was confined in the nucleus prior to 7 days in culture, as shown by immunofluorescence staining (upper panels of Fig. 5b). However, the amount of TDP-43 was greater in the cytosol of $(\mathrm{N} 390 \mathrm{D} /+) \mathrm{MN}$ on day 14 in culture, but without TDP43 aggregate formation, as shown in the lower panels of Fig. 5b. This observation was similar to that of the symptomatic spinal cord MN of N390D/+ male mice (Fig. 3c). On the other hand, the level of TDP-43 in ESC-derived mutant $(\mathrm{A} 315 \mathrm{~T} /+) \mathrm{MN}$ was 2- to 4-fold higher than the $(+/+) \mathrm{MN}$ on day 7 and day 14 , respectively. Interestingly, despite of the significant reduction of average axonal lengths of the mutant $\mathrm{MN}$ after day 14 in culture, the level of TDP-43 in mutant (N390D/+) MN was 6- 
a

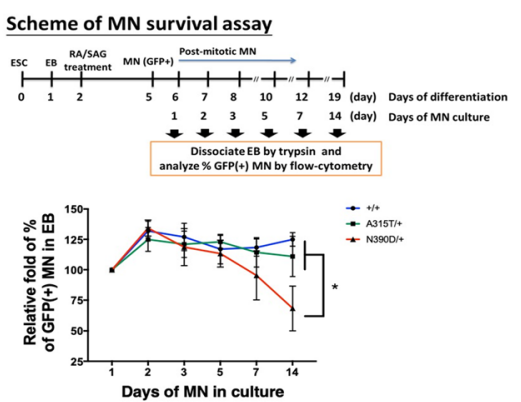

b
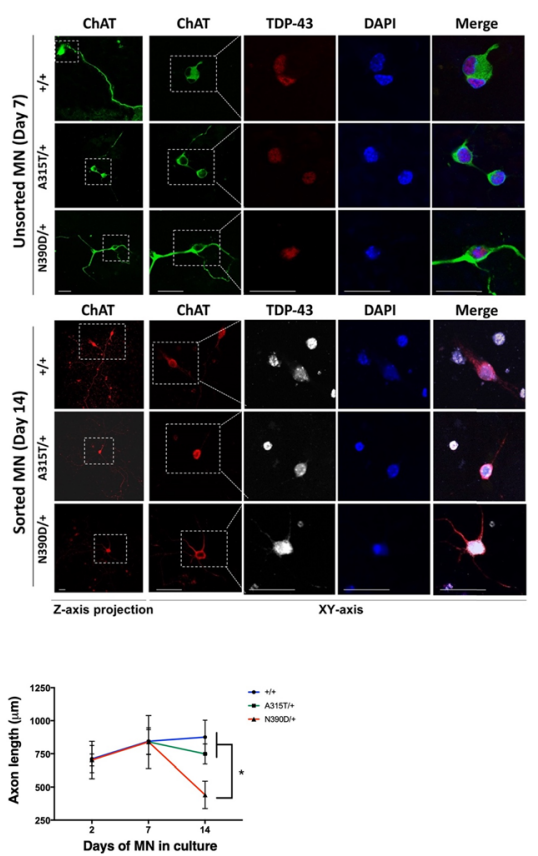

d
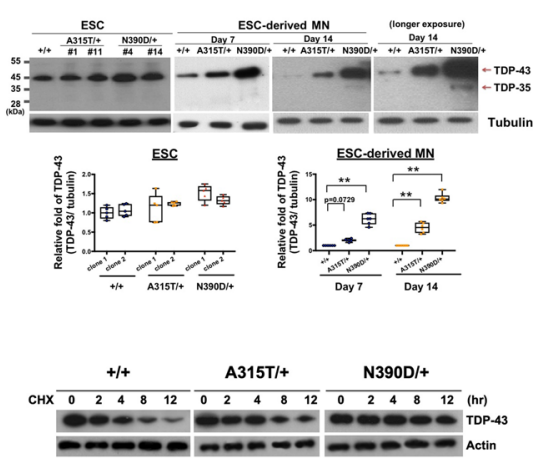

MN (Day3)

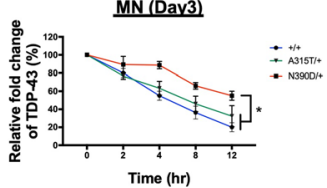

Fig. 5 Comparative analysis of patho-signatures and neurodegeneration of cultured spinal cord MN derived from +/+ and mutant ESC. a Survival curves of MN in culture. The percentage(s) of GFP (+) cells in the cell mixtures on day 1 of MN culture is defined as 1. The data showed that (N390D/+) MN became more vulnerable to death than (A315T/+) MN or (+/+) MN on day 14 in culture. Mean $\pm S D{ }^{*} p<0.05$. b Immunofluorescence co-staining analysis of MN on day 7 and day 14 in culture using anti-ChAT (green or red) and anti-TDP-43 (red or white). The white boxes in the panels of the first column mark the areas magnified for higher resolution. The axonal morphology under lower magnified field is displayed with Z-axis projection. The scale bars are $50 \mu \mathrm{m}$. c The statistical analysis of the axon lengths from the WT and mutant MN on different days in culture is shown in the line graph. $N>50$. ${ }^{*} p<0.05$. d Comparison of the levels of TDP-43 at early stages of ESC-derived MN in culture (from day 1 to day 3), as analyzed by Western blotting. The statistical analysis is shown in the lower scatter plot (mean $\pm \mathrm{SD}) .{ }^{*} p<0.05$. e The stability of TDP-43 polypeptides in spinal cord (N390D/+) MN, (A315T/+) MN, and (+/+) MN on day 2 in culture by cycloheximide (CHX) assay and Western blotting analysis. The graph below the blots shows that TDP-43 is more stable in (N390D/+) MN in comparison to either (+/+) MN or to $(\mathrm{A} 315 \mathrm{~T} /+) \mathrm{MN} .{ }^{*} p<0.05$

and 11-fold higher than $(+/+) \mathrm{MN}$ on culture day 7 and day 14, respectively, with the appearance of TDP-35 species on day 14 in culture (Fig. $5 \mathrm{~d}$ ). The higher amount of TDP43 in mutant MN could be in part due to increased stability of the mutant TDP-43 protein (Fig. 5e). Thus, the analysis of cultured MN derived from ESC suggests that timedependent, spinal cord MN-autonomous toxic effects underlie the role of the N390D mutation of TDP-43 in agedependent ALS-like pathogenesis of N390D/+ mice.

\section{Increase of Bcl-2 mRNA and Bcl-2 protein in cultured (N390D/+) MN}

Significantly, in parallel to the time-dependent increase of the TDP-43 level (Fig. 6a), there was an increase of either $\mathrm{Bcl}-2$ mRNA 201 or Bcl-2 protein in the cultured $(\mathrm{N} 390 \mathrm{D} /+) \mathrm{MN}$ (Fig. $6 \mathrm{~b}$ and c) resulting from misregulation of the alternative splicing of $\mathrm{Bcl}-2$ pre-mRNA (Fig. 6d). On the other hand, the levels of $B c l-2$ mRNA 201 and $\mathrm{Bcl}-2$ protein in $(\mathrm{A} 315 \mathrm{~T} /+) \mathrm{MN}$ were similar compared to those of $(+/+) \mathrm{MN}$ on culture after day 2 (Fig. 6b) and day 14 (data not shown), despite of the increase of TDP-43 in cultured (A315T/+) MN (Fig. 6a). The data of Figs. 4 and 6 together indicate that there are cell-autonomous mis-regulation of $\mathrm{Bcl}-2$ pre-mRNA splicing and consequent increase of $\mathrm{Bcl}-2$ protein in (N390D/+) MN as caused by the increased level of TDP43. Furthermore, there is a lag between the time on-set of $\mathrm{Bcl}-2$ protein increase and $\mathrm{MN}$ degeneration.

\section{Changes of calcium ion homeostasis in cultured (N390D/+) MN}

Since Bcl-2 is known to increase ER calcium ion leakage resulting in overloading of the cytosolic calcium ion 
$\mathbf{a}$

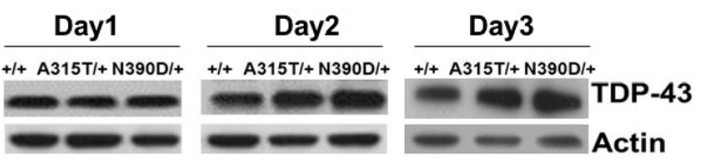

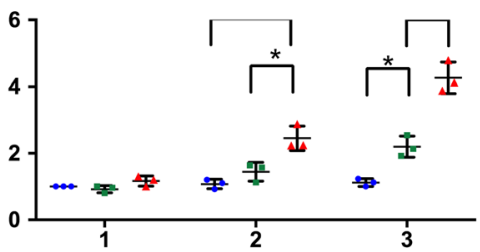

b
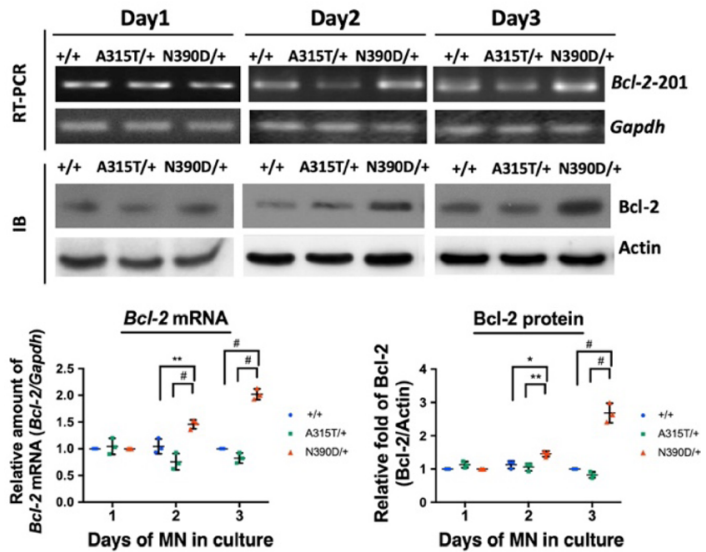

c
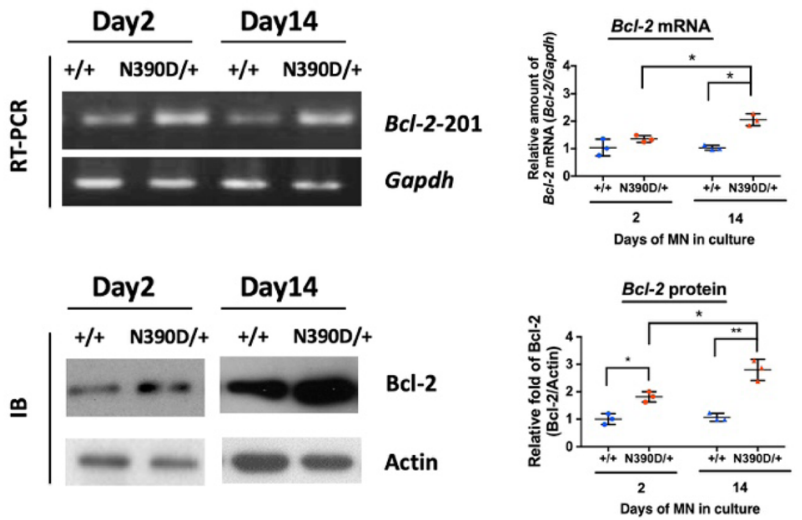

d
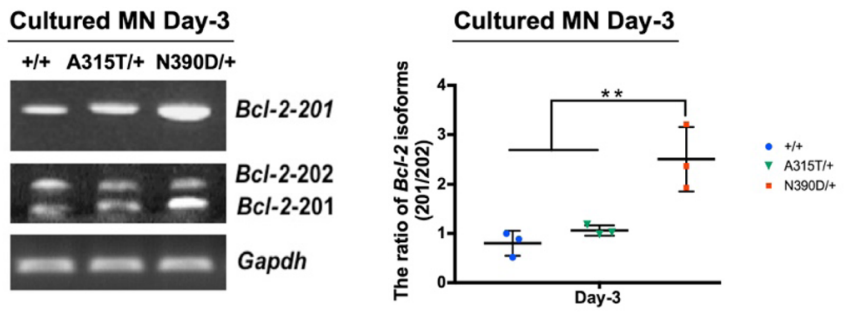

e
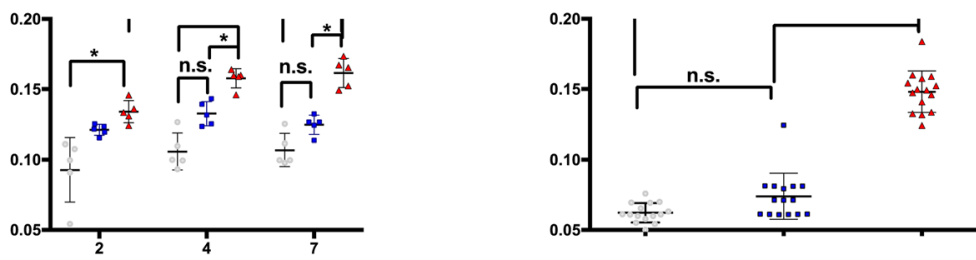

Fig. 6 (See legend on next page.) 
(See figure on previous page.)

Fig. 6 Mis-regulation of BCl-2 expression and calcium ion homeostasis in cultured (N390D/+) MN. a Comparison of the levels of TDP-43 at early stages of ESC-derived MN in culture (from day 1 to day 3), as analyzed by Western blotting. The statistical analysis is shown in the lower scatter plot (mean \pm SD). $\mathbf{b}$ Comparison of the expression levels of BCl-2-201mRNA and BCl-2 protein as analyzed by RT-PCR (exemplified in the upper panels) and Western blotting (exemplified in the middle panels), respectively. The statistical analysis is shown in the lower scatter plots (mean \pm SD). c Comparison of the levels of $B C l-2$ mRNA by RT-PCR (upper panel) and BCl-2 protein by Western blotting (lower panel) and in cultured (+/+) $\mathrm{MN}$ and (N390D/+) MN on day 2 and day 14, respectively. $\mathbf{d}$ RT-PCR detection and statistical analysis (left scatter plot, mean \pm SD) of the changes of the relative ratio of the two BCl-2 mRNA isoforms. Note the increase of functional BCl-2 -201 mRNA in the spinal cord of N390D/+ male mice at both pre-symptomatic (3-month) and symptomatic (6-month) stages. $N=3$ (randomly chosen from each of the two independent lines) per group. e The relative levels of the cytosolic calcium ion levels in cultured MN (left plot) and transfected HEK-293 T cells (right plot) overexpressing human TDP-43(wild-type; WT), TDP-43 (A315T) or TDP-43 (N390D). The relative calcium ion levels were analyzed with the use of Fura2-AM reagent and compared in the separated scatter plots (mean \pm SD). Note the overloading of the cytosolic calcium ion in cultured (N390D/+) MN and in HEK-293 T cells overexpressing TDP-43 (N390D) in comparison to TDP-43 (WT) and TDP-43 (A315T). Significantly different represented in ae: ${ }^{*} p<0.05,{ }^{* *} p<0.01, \# p<0.001$. n.S., not significant

$\left(\mathrm{Ca}^{2+}\right)[7,46]$, we examined the intracellular level of calcium ion in ESC and ESC-derived spinal MN. As seen, the cytosolic calcium ion concentrations in the (N390D/+) ESC-derived MN was higher than those derived from $(+/+)$ ESC or (A315T/+) ESC (Fig. 6e, left panel), despite similar concentration of calcium ion in $(+/+)$ ESC, $(\mathrm{A} 315 \mathrm{~T} /+)$ ESC and $(\mathrm{N} 390 \mathrm{D} /+)$ ESC (data not shown). Furthermore, overexpression of human TDP-43 (N390D) provoked the intracellular level of calcium ion in HEK293T cells, but not in those cells overexpressing similar amount of either wild-type TDP43 or TDP-43 (A315T) (Fig. 6e, right panel). A previous study [43] also provided relevant evidence that $\mathrm{Bcl}-2$ was involved in neurotoxicity. In particular, knockdown of Bcl-2 by siRNA in stable clones of HEK-293 cells expressing mutant TDP-43 (A382T) or TDP-43 (M337 V) would decrease the mislocalizaiton of TDP- 43 and reduce $\mathrm{Ca}^{2+}$ release from ER. Thus, neurotoxicity indeed could be caused by up-regulation of Bcl-2 protein. The above data taken together show that elevation of the cellular level of TDP-43 (N390D) would increase the intracellular cytosolic calcium ion concentration as a result of the increase of $\mathrm{Bcl}-2$ protein.

\section{Conclusion}

The availability of appropriate ALS mouse models is essential for understanding ALS disease mechanisms and the development of therapeutic drugs. Most of previously developed ALS-TDP mouse models are based on a transgenic approach, whereby wild type or mutant TDP-43 is expressed under the control of different promoters $[18,23,40,63]$. This approach is limited by the cell type specificity of the promoters used to express the wild type and mutant TDP-43 transgenes, so the timing and level of the transgene expression is difficult to control. Furthermore, transgene over-expression causes neurotoxicity and other side effects due to the differences in the timing and level of the transgene expression, even with the wild type TDP-43 gene. Here we describe the use of knockin strategy to study ALS pathogenesis as a consequence of different ALS-associated TDP-43 mutations. A comparison of the pathologies of two heterozygous mouse models, $\mathrm{N} 390 \mathrm{D} /+$ and $\mathrm{A} 315 \mathrm{~T} /+$ that we have generated to those knock-in mouse models reported in literature [24, 26, 72] demonstrate the distinctive pathological effects of different TDP-43 mutants. More importantly, the TDP-43(N390D/ +) mice appear to be a genuine ALS-TDP model for further basic and translational research of ALS-TDP.

It is somewhat unexpected but not totally surprising that in the genetic background of C57BL/6 J mice, only N390D but not A315T mutation of TDP-43 exhibits a dominant causative role in ALS-TDP pathogenesis (Fig. 1). A315T is an extensively studied fALS mutation. Analysis of transgenic rodent models or transfected cell cultures have suggested that overexpression of human TDP- $43^{\mathrm{A} 315 \mathrm{~T}}$ causes neuron degeneration [71] and dosage-dependent cytotoxicity [75], induces ER stress [67], and affects neuronal mitochondrial morphology [70]. However, mice expressing human TDP-43 ${ }^{\mathrm{A} 315 \mathrm{~T}}$ under the control of endogenous mouse Tarabp promoter develop mitochondria dysfunction but without obvious others phenotypes [61]. It has been suggested that variations in the ALS-TDP pathological phenotypes among the ALS-TDP patients result from their different genetic background as well as from environmental factors $[9,77]$. The lack of ALS pathology of this mouse model and our A315T mice could reflect the differential effects of the mouse and human genetic backgrounds on the development of ALS pathogenesis. It is also worthy to note that the N390D/+ mice and A315T mice investigated in the current study are all in the B6 background. Their phenotypes are likely to change under a different genetic background, as shown before for several other genetically modified neurodegenerative disease mouse models, e.g. the transgenic $\mathrm{AD}$ mouse model $5 \mathrm{xFAD}$ (database, by Jackson Lab) and the mice carrying TDP-43 mutations induced by ENU [26].

In striking contrast to heterozygous A315T (this study), Q331K [72], M337 V and G298S [24] knock-in mice, the heterozygous N390D/ + male mice develop molecular, cellular, and behavioral changes, with a spectrum of ALS- 
like phenotypes that appear at the age the 6 months and then progress (Fig. 7). These phenotypes include shortened life span (Fig. 1b), body weight loss of the remains (Fig. 1c), age-dependent motor dysfunction (Fig. 2a), kyphosis (Fig. 2c), muscle atrophy (Fig. 2d and e) and denervation of NMJ (Fig. 2f). The lack of body weight loss in N390D/+ mice is similar to the Q331K knock-in mouse model the basis of which has been attributed to hyperphagia and transcriptomic changes [72]. Notably, other TDP43 disease models have been shown to have increased body fat, decreased lean muscle mass, and larger adipocytes in white fat [60]. Therefore, we guess that maintenance of the body weight in N390D/+ mice might also be due to some of these effects. In the case of the N390D/+ male mice, good care of the diseased mice (see Methods) likely also has contributed to the maintenance of their body weight throughout life.

Accompanied with these phenotypes are various molecular and cellular pathologies (Fig. 7) including the progressive increases of spinal cord TDP-43/ TDP-35/ TDP-25 (Fig. 3a and b), insoluble TDP-43 species (Fig. 3b), pTDP-43 (Additional file 4: Figure S4), and the accumulation of cytosolic TDP-43/ pTDP-43 aggregates in the spinal cord MN of symptomatic N390D/+ male mice (Fig. 3c and $\mathrm{d}$, and Additional file 4: Figure S4, d-g). Ubiquitinated proteins also increased in the spinal cord $\mathrm{MN}$ and they are partially colocalized with the cytosolic TDP-43/ pTDP-43 aggregates (Fig. 3c and d, and Additional file 4: Figure S4, $\mathrm{d}$-g). The reactive astrocytes surrounding the degenerating motor neurons in the spinal cord of ALS have suggested a crucial role of astrogliosis in ALS pathology [52]. However, astrogliosis could only be detected in the spinal cord of $\mathrm{N} 390 \mathrm{D} /+$ mice at late stage of pathogenesis (Additional file 5: Figure S5). It is noteworthy that similar to the heterozygous Q331K/+ knock-in mice [26, 72], N390D/+ male mice still have an average age of $\sim 19$ months despite of the loss of $30 \%$ of their spinal MN already at the age of 6 months and neurodegeneration of the primary motor cortex at the ages of 12 to 24 months. Besides the possible effects of the B6 genetic background, good care of the mice (see Methods) should also have contributed to the life span of N390D/+ male mice.

There are also progressive changes of autophagy and UPS in the spinal cord of N390D/+ mice. Interestingly, the LC3-II/LC3-I ratio in pre-symptomatic (3-month old) N390D/+ male mice is higher than that of the wildtype male mice (Fig. 4a), which we speculate to be due to an initial autophagy response to the TDP- 43 mismetabolism [54]. In any case, the decreased autophagy function in the spinal cord of symptomatic N390D/+

\section{TDP-43 (N390D/+) male mice}

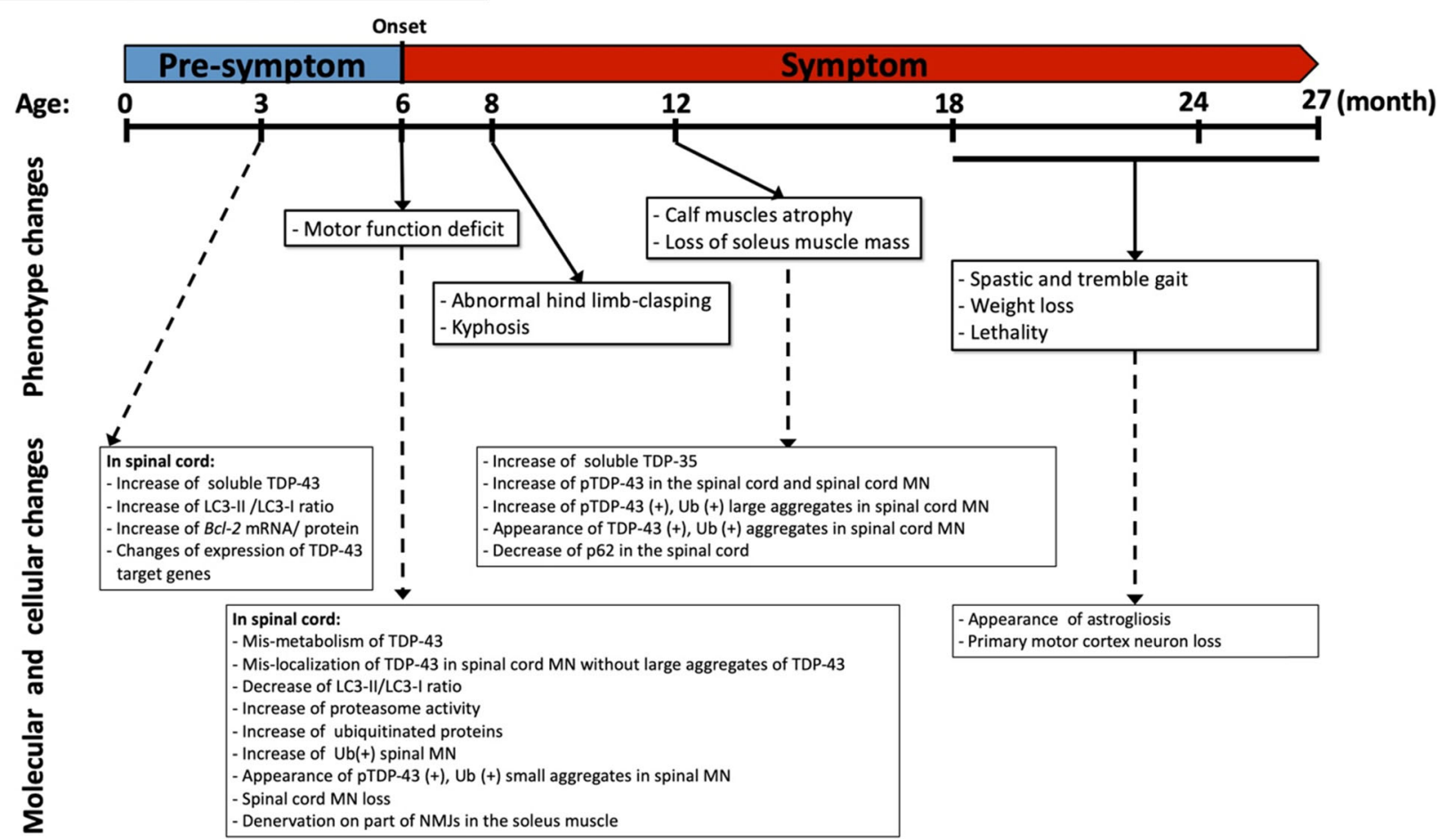

Fig. 7 Age-dependent ALS-TDP-like pathogenesis of TDP-43 (N390D/+) male mice. The timeline (month) illustrates the major morphological, behavioral, cellular, and molecular events during the pre-symptomatic and symptomatic stages of heterozygous male TDP-43 (N390D/+) mice. For more details, see text 
mice, as reflected by the decreased ratio of LC3-II/ LC3-I (Fig. 4a) and p62 level (Additional file 6: Figure S6), would contribute to the pathology progression and eventual death of the spinal cord MN (Fig. 3c and d). On the other hand, there is an enhancement of UPS in the spinal cord during pathogenesis of the $\mathrm{N} 390 \mathrm{D} /+$ male mice, as reflected by the proteasome activity assay (Additional file 6: Figure S6c and d). This increase of UPS in the symptomatic spinal cord of N390D/+ male mice could compensate for the down regulation of autophagy as suggested before for other systems [68].

There is an autoregulation program for the control of the amount of the TDP- 43 protein through regulation of the Tardbp mRNA decay and/or processing $[5,35]$. However, the TDP-43 protein accumulates in the spinal cord $\mathrm{MN}$ of N390D/+ male mice in part due to increased stability of the TDP-43 (N390D) polypeptide (Fig. 5e) and Wu et al., 2013 [75] but without obvious change of the Tardbp mRNA level (Additional file 3: Figure S3, a and b). This is in contrast to the increase of the Tardbp mRNA in the Q331K knock-in mouse model [72], the RRM2mut plus LCDmut ENU mouse models [26] as well as the TDP-43 (A315T) transgenic mouse model [4]. Noteworthy, normal autoregulatory function was also observed in knock-in mouse models carrying ALS-associated M337 V or G298S mutation [24]. In addition, human iPSCs carrying different TDP-43 mutations exhibited a wide range of their Tardbp mRNA levels [25]. Thus, different ALSassociated mutations in the $\mathrm{C}$-terminal glycine-rich domain exert differential effects on the autoregulation of TDP-43 protein via metabolism of the Tardbp mRNA.

Of particular interest and importance is the finding of the concomitant increase of the levels of TDP-43 and the $\mathrm{Bcl}-2 \mathrm{mRNA} 201$ encoding the $26 \mathrm{kDa} \mathrm{Bcl}-2$ protein in the spinal cord of 3-month, 6-month and 12-month old, but not the newborn, N390D/+ male mice (Fig. 4b and c) as well as in cultured spinal cord (N390D/+) MN at differentiation day 2 and beyond (Fig. 6a-c). Bcl-2 is an antiapoptotic protein that promotes the survival of neurons [51] and other types of cells [31]. It is also known to affect autophagy [43], intracellular calcium ion homeostasis [7], and consequently the associated cell-fate determining pathways $[22,29]$ in a dose-dependent manner. Whether a similar effect of TDP-43(N390D) on Bcl-2 RNA processing operated in human awaits to be seen in future. Also, the causative effect by elevated TDP-43 (N390D) protein on the alteration of $\mathrm{Bcl}-2$ pre-mRNA splicing and consequent increase of the $\mathrm{Bcl}-2$ protein was not observed for TDP-43(A315T) (Fig. 4c-e), and TDP-43 (A382T) or TDP-43 (M337 V) [54]. Whether it could also be exerted by other ALS-associated TDP-43 mutations is unknown at the present time.

Overall, our data indicate that spinal cord-specific increase of TDP-43 (N390D), due in part to its higher stability, and the associated of gain-of-toxicity in $\mathrm{Bcl}-2$ pre-mRNA splicing are among the essential early causative events of ALS pathogenesis of the TDP-43 (N390D/ + ) mice. This leads to upregulation of the Bcl-2 protein, change of autophagy, mis-metabolism of TDP-43 and other proteins, ER stress, etc., all of which would contribute to the age-dependent cytotoxicity/ death of the spinal cord MN and other age-dependent ALS-like phenotypes TDP-43 (N390D/+) mice.

The establishment and comparative analysis of the two mouse models, TDP-43 (N390D/+) and TDP-43 $(\mathrm{A} 315 \mathrm{~T} /+)$, suggest that different human ALSassociated TDP-43 mutations display distinct pathophysiological changes in mice. The TDP-43 (N390D/ +) mice should provide an excellent model to study in detail the initiation and propagation of ALS-TDP under normal physiological conditions. It would also be ideal for use in the validation of potential therapeutic approaches and reagents for the treatment of ALS-TDP.

\section{Supplementary information}

Supplementary information accompanies this paper at https://doi.org/10. 1186/s40478-020-0881-5.

Additional file 1: Figure S1. Effects of N390D mutations on the survival of newborn pups and on motor function/ lifespan of N390D/+ female mice.

Additional file 2: Figure S2. Cognition analysis of N390D/+ male mice. Additional file 3: Figure S3. Similar levels of Tardbp mRNA expression in different tissues of +/+, A315T/+ and N390D/+ male mice.

Additional file 4: Figure S4. Increase of phosphorylated TDP-43 (pTDP43 ) in the spinal cord, and loss of $\mathrm{NeuN}(+)$ neurons of primary motor cortex of the old N390D/+ male mice.

Additional file 5: Figure S5. Increase of astrogliosis in the spinal cord of N390D/+ male mice at late stage of pathogenesis.

Additional file 6: Figure S6. Decreased of p62 protein level and enhanced of the proteasome activities in the spinal cord, but not the forebrain, of symptomatic N390D/+ mice.

Additional file 7: Figure S7. Expression change of $\mathrm{BCl}-2$ and other TDP43 target genes in the spinal cord of N390D/+ male mice in comparison to the $+/+$ male mice.

Additional file 8: Figure S8. Scheme of MN differentiation.

Additional file 9: Movie S1. 18-month old N390D/+ mouse (\#108). Note the 18-month old N390D/+ mice (Additional file 9: Movie S1 and Additional file 10: Movie S2) but not +/+ littermate (Additional file 11: Movie S3) exhibit spastic and tremble gait. Some of them show difficult movement due to paralysis of the hind limbs (Additional file 10: Movie S2).

Additional file 10: Movie S2. 18-month old N390D/+ mouse (\#361). Note the 18-month old N390D/+ mice (Additional file 9: Movie S1 and Additional file 10: Movie S2) but not +/+ littermate (Additional file 11: Movie S3) exhibit spastic and tremble gait. Some of them show difficult movement due to paralysis of the hind limbs (Additional file 10: Movie S2).

Additional file 11: Movie S3. 18-month old +/+ littermate of N390D/+ mouse (\#361). Note the 18-month old N390D/+ mice (Additional file 9: Movie S1 and Additional file 10: Movie S2) but not +/+ littermate (Additional file 11: Movie S3) exhibit spastic and tremble gait. Some of them show difficult movement due to paralysis of the hind limbs (Additional file 10: Movie S2). 


\section{Acknowledgments}

We thank many of our colleagues for their helpful suggestions and critical comments during the course of this work. We appreciate the efforts by Tom Maniatis and Valeria Gerbino at Columbia University in helping us to revise the manuscript. We are grateful Dr. Jun-An Chen and his lab members of Institute of Molecular Biology at Academia Sinica for the help and suggestion of experimental methods such as mouse ESC culture, spinal MN differentiation and NMJ whole mount staining. We also thank Dr. Bo-Tsang Huang of Institute of Biomedical Sciences at Academia Sinica for help the knowledge of identification soleus and NMJ staining. The technical assistance efforts by the personnel of the Transgenic Core Facility, Confocal Microscope Core, the FACS Facility and the Electrophysiology and Calcium Imaging Core Facility of the Institute of Molecular Biology at Academia Sinica, in particular Ching-Yen Tsai, Sue-Ping Lee, Shu-Mei Huang and Ya-Min Lin, are greatly appreciated. The study has been supported by the Academia Sinica and a Frontier of Science grant from the Ministry of Science and Technology, Taipei, Taiwan, R.O.C. C.-K. J. Shen is an Investigator Awardee of the Academia Sinica.

\section{Authors' contributions}

C-KJS and S-LH designed the experiments and wrote the manuscript. S-LH performed experiments including the generation and phenotypic characterization of N390D/+ and A315T/+ mice. L-SW designed the strategy for knock-in mice generation and the carried out IF staining of spinal cord sections for gliosis study. ML and P-LC performed the proteasome activity assay, C-WC contributed to the generation of A315T/+ mice and behavioral tests of A315T/+ mice. L-SW, C-WC and W-CC contributed to the genotype screening and DNA sequencing of ESC for microinjection. Y-RC and Y-SF provided the sample of in vitro phosphorylated TDP-43. All authors read and approved the final manuscript.

\section{Competing interests}

The authors declare that they have no competing interests.

\section{Author details}

'Institute of Molecular Biology, Academia Sinica, Taipei 11529, Taiwan, Republic of China. Institute of Molecular Medicine, College of Medicine, National Taiwan University, Taipei 10002, Taiwan, Republic of China. ${ }^{3}$ Graduate Institute of Neural Regenerative Medicine, College of Medical Science and Technology, Taipei Medical University, Taipei 11031, Taiwan, Republic of China. ${ }^{4}$ Genomics Research Center, Academia Sinica, Taipei 11529, Taiwan, Republic of China.

\section{Received: 23 October 2019 Accepted: 10 December 2019} Published online: 21 January 2020

\section{References}

1. Afroz T et al (2017) Functional and dynamic polymerization of the ALS-linked protein TDP-43 antagonizes its pathologic aggregation. Nat Commun 8(1):45

2. Alami NH et al (2014) Axonal transport of TDP-43 mRNA granules is impaired by ALS-causing mutations. Neuron 81(3):536-543

3. Arnold ES et al (2013) ALS-linked TDP-43 mutations produce aberrant RNA splicing and adult-onset motor neuron disease without aggregation or loss of nuclear TDP-43. Proc Natl Acad Sci U S A 110(8):E736-E745

4. Avendano-Vazquez SE et al (2012) Autoregulation of TDP-43 mRNA levels involves interplay between transcription, splicing, and alternative polyA site selection. Genes Dev 26(15):1679-1684

5. Ayala YM et al (2008) Structural determinants of the cellular localization and shuttling of TDP-43. J Cell Sci 121(Pt 22):3778-3785

6. Bilican B et al (2012) Mutant induced pluripotent stem cell lines recapitulate aspects of TDP-43 proteinopathies and reveal cell-specific vulnerability. Proc Natl Acad Sci U S A 109(15):5803-5808

7. Bonneau B et al (2013) Non-apoptotic roles of Bcl-2 family: the calcium connection. Biochim Biophys Acta 1833(7):1755-1765

8. Bose JK, Huang CC, Shen CK (2011) Regulation of autophagy by neuropathological protein TDP-43. J Biol Chem 286(52):44441-44448

9. Bozzoni $V$ et al (2016) Amyotrophic lateral sclerosis and environmenta factors. Funct Neurol 31(1):7-19

10. Buratti E (2015) Functional significance of TDP-43 mutations in disease. Adv Genet 91:1-53
11. Buratti E, Baralle FE (2012) TDP-43: gumming up neurons through proteinprotein and protein-RNA interactions. Trends Biochem Sci 37(6):237-247

12. Chen JA et al (2011) Mir-17-3p controls spinal neural progenitor patterning by regulating Olig2/Irx3 cross-repressive loop. Neuron 69(4):721-735

13. Chia R, Chio A, Traynor BJ (2018) Novel genes associated with amyotrophic lateral sclerosis: diagnostic and clinical implications. Lancet Neurol 17(1):94-102

14. Chiang PM et al (2010) Deletion of TDP-43 down-regulates Tbc1d1, a gene linked to obesity, and alters body fat metabolism. Proc Natl Acad Sci U S A 107(37):16320-16324

15. Chou SM, Norris FH (1993) Amyotrophic lateral sclerosis: lower motor neuron disease spreading to upper motor neurons. Muscle Nerve 16(8):864-869

16. Coyne AN et al (2014) Futsch/MAP 1B mRNA is a translational target of TDP-43 and is neuroprotective in a Drosophila model of amyotrophic lateral sclerosis. J Neurosci 34(48):15962-15974

17. Dadon-Nachum M, Melamed E, Offen D (2011) The "dying-back" phenomenon of motor neurons in ALS. J Mol Neurosci 43(3):470-477

18. D'Alton $S$ et al (2014) Divergent phenotypes in mutant TDP-43 transgenic mice highlight potential confounds in TDP-43 transgenic modeling. PLoS One 9(1):e86513

19. Dang K et al (2016) Stable atrogin-1 (Fbxo32) and MuRF1 (Trim63) gene expression is involved in the protective mechanism in soleus muscle of hibernating Daurian ground squirrels (Spermophilus dauricus). Biol Open 5(1):62-71

20. de Jong $S$ et al (2013) Endogenous female reproductive hormones and the risk of amyotrophic lateral sclerosis. J Neurol 260(2):507-512

21. Deacon RM, Rawlins JN (2006) T-maze alternation in the rodent. Nat Protoc $1(1): 7-12$

22. Distelhorst CW, Bootman MD (2011) BCl-2 interaction with the inositol 1,4,5trisphosphate receptor: role in $\mathrm{Ca}(2+)$ signaling and disease. Cell Calcium 50(3):234-241

23. Ditsworth D et al (2017) Mutant TDP-43 within motor neurons drives disease onset but not progression in amyotrophic lateral sclerosis. Acta Neuropathol 133(6):907-922

24. Ebstein SY, Yagudayeva I, Shneider NA (2019) Mutant TDP-43 causes earlystage dose-dependent motor neuron degeneration in a TARDBP knockin mouse model of ALS. Cell Rep 26(2):364-373 e4

25. Egawa $\mathrm{N}$ et al (2012) Drug screening for ALS using patient-specific induced pluripotent stem cells. Sci Transl Med 4(145):145ra104

26. Fratta $P$ et al (2018) Mice with endogenous TDP-43 mutations exhibit gain of splicing function and characteristics of amyotrophic lateral sclerosis. EMBO J 37(11):e98684

27. Gitcho MA et al (2008) TDP-43 A315T mutation in familial motor neuron disease. Ann Neurol 63(4):535-538

28. Goto A et al (2013) Up-regulation of adiponectin expression in antigravitational soleus muscle in response to unloading followed by reloading, and functional overloading in mice. PLoS One 8(12):e81929

29. Greenberg EF, Lavik AR, Distelhorst CW (2014) BCl-2 regulation of the inositol 1,4,5-trisphosphate receptor and calcium signaling in normal and malignant lymphocytes: potential new target for cancer treatment. Biochim Biophys Acta 1843(10):2205-2210

30. Guyenet SJ et al (2010) A simple composite phenotype scoring system for evaluating mouse models of cerebellar ataxia. J Vis Exp 39:e1787

31. Hardwick JM, Soane $L$ (2013) Multiple functions of BCL-2 family proteins. Cold Spring Harb Perspect Biol 5(2):a008722

32. Igaz LM et al (2011) Dysregulation of the ALS-associated gene TDP-43 leads to neuronal death and degeneration in mice. J Clin Invest 121(2):726-738

33. Kabashi E et al (2008) TARDBP mutations in individuals with sporadic and familial amyotrophic lateral sclerosis. Nat Genet 40(5):572-574

34. Kasai T et al (2009) Increased TDP-43 protein in cerebrospinal fluid of patients with amyotrophic lateral sclerosis. Acta Neuropathol 117(1):55-62

35. Koyama A et al (2016) Increased cytoplasmic TARDBP mRNA in affected spinal motor neurons in ALS caused by abnormal autoregulation of TDP-43. Nucleic Acids Res 44(12):5820-5836

36. Lee EB, Lee VM, Trojanowski JQ (2011) Gains or losses: molecular mechanisms of TDP43-mediated neurodegeneration. Nat Rev Neurosci 13(1):38-50

37. Li HF, Wu ZY (2016) Genotype-phenotype correlations of amyotrophic lateral sclerosis. Transl Neurodegener 5:3

38. Ling SC, Polymenidou M, Cleveland DW (2013) Converging mechanisms in ALS and FTD: disrupted RNA and protein homeostasis. Neuron 79(3):416-438 
39. Ling SC et al (2010) ALS-associated mutations in TDP-43 increase its stability and promote TDP-43 complexes with FUS/TLS. Proc Natl Acad Sci U S A 107(30):13318-13323

40. Liu YC, Chiang PM, Tsai KJ (2013) Disease animal models of TDP-43 proteinopathy and their pre-clinical applications. Int J Mol Sci 14(10):20079-20111

41. Majumder $\mathrm{P}$ et al (2012) TDP-43 regulates the mammalian spinogenesis through translational repression of Rac1. Acta Neuropathol 124(2):231-245

42. Majumder $P$ et al (2016) Co-regulation of mRNA translation by TDP-43 and fragile X syndrome protein FMRP. Acta Neuropathol 132(5):721-738

43. Marquez RT, Xu L (2012) Bcl-2:Beclin 1 complex: multiple, mechanisms regulating autophagy/apoptosis toggle switch. Am J Cancer Res 2(2): 214-221

44. Mazzoni EO et al (2013) Saltatory remodeling of Hox chromatin in response to rostrocaudal patterning signals. Nat Neurosci 16(9):1191-1198

45. McGoldrick P et al (2013) Rodent models of amyotrophic lateral sclerosis. Biochim Biophys Acta 1832(9):1421-1436

46. Mutihac $R$ et al (2015) TARDBP pathogenic mutations increase cytoplasmic translocation of TDP-43 and cause reduction of endoplasmic reticulum $\mathrm{Ca}(2)(+)$ signaling in motor neurons. Neurobiol Dis 75:64-77

47. Nakamizo T et al (2000) Protection of cultured spinal motor neurons by estradiol. Neuroreport 11(16):3493-3497

48. Neumann M et al (2006) Ubiquitinated TDP-43 in frontotemporal lobar degeneration and amyotrophic lateral sclerosis. Science 314(5796):130-133

49. Neumann M et al (2007) TDP-43-positive white matter pathology in frontotemporal lobar degeneration with ubiquitin-positive inclusions. J Neuropathol Exp Neurol 66(3):177-183

50. Orsini $\mathrm{M}$ et al (2015) Amyotrophic lateral sclerosis: new perpectives and update. Neurol Int 7(2):5885

51. Pfisterer U, Khodosevich K (2017) Neuronal survival in the brain: neuron type-specific mechanisms. Cell Death Dis 8(3):e2643

52. Philips T, Rothstein JD (2014) Glial cells in amyotrophic lateral sclerosis. Exp Neurol 262 Pt B:111-120

53. Polymenidou M et al (2011) Long pre-mRNA depletion and RNA missplicing contribute to neuronal vulnerability from loss of TDP-43. Nat Neurosci 14(4): 459-468

54. Prentice H, Modi JP, Wu JY (2015) Mechanisms of neuronal protection against excitotoxicity, endoplasmic reticulum stress, and mitochondrial dysfunction in stroke and neurodegenerative diseases. Oxidative Med Cell Longev 2015:964518

55. Prudencio M et al (2015) Distinct brain transcriptome profiles in C9orf72associated and sporadic ALS. Nat Neurosci 18(8):1175-1182

56. Scotter EL, Chen HJ, Shaw CE (2015) Erratum to: TDP-43 proteinopathy and ALS: insights into disease mechanisms and therapeutic targets. Neurotherapeutics 12(2):515-518

57. Scotter EL et al (2014) Differential roles of the ubiquitin proteasome system and autophagy in the clearance of soluble and aggregated TDP-43 species. J Cell Sci 127(Pt 6):1263-1278

58. Sephton CF et al (2011) Identification of neuronal RNA targets of TDP-43containing ribonucleoprotein complexes. J Biol Chem 286(2):1204-1215

59. Shoji $\mathrm{H}$ et al (2012) T-maze forced alternation and left-right discrimination tasks for assessing working and reference memory in mice. J Vis Exp 60:e3300

60. Stallings NR et al (2013) TDP-43, an ALS linked protein, regulates fat deposition and glucose homeostasis. PLoS One 8(8):e71793

61. Stribl C et al (2014) Mitochondrial dysfunction and decrease in body weight of a transgenic knock-in mouse model for TDP-43. J Biol Chem 289(15): 10769-10784

62. Tremblay E, Martineau E, Robitaille R (2017) Opposite synaptic alterations at the neuromuscular junction in an ALS mouse model: when motor units matter. J Neurosci 37(37):8901-8918

63. Tsai KJ et al (2010) Elevated expression of TDP-43 in the forebrain of mice is sufficient to cause neurological and pathological phenotypes mimicking FTLD-U. J Exp Med 207(8):1661-1673

64. Tsao W et al (2012) Rodent models of TDP-43: recent advances. Brain Res 1462:26-39

65. Tsuiji $\mathrm{H}$ et al (2017) TDP-43 accelerates age-dependent degeneration of interneurons. Sci Rep 7(1):14972

66. van den Bos MAJ et al (2019) Pathophysiology and diagnosis of ALS: insights from advances in neurophysiological techniques. Int J Mol Sci 20(11):2818
67. Walker AK et al (2013) ALS-associated TDP-43 induces endoplasmic reticulum stress, which drives cytoplasmic TDP-43 accumulation and stress granule formation. PLoS One 8(11):e81170

68. Wang C, Wang X (2015) The interplay between autophagy and the ubiquitin-proteasome system in cardiac proteotoxicity. Biochim Biophys Acta 1852(2):188-194

69. Wang IF et al (2008) TDP-43, the signature protein of FTLD-U, is a neuronal activity-responsive factor. J Neurochem 105(3):797-806

70. Wang $W$ et al (2013) The ALS disease-associated mutant TDP-43 impairs mitochondrial dynamics and function in motor neurons. Hum Mol Genet 22(23):4706-4719

71. Wegorzewska I et al (2009) TDP-43 mutant transgenic mice develop features of ALS and frontotemporal lobar degeneration. Proc Natl Acad Sci U S A 106(44):18809-18814

72. White MA et al (2018) TDP-43 gains function due to perturbed autoregulation in a Tardbp knock-in mouse model of ALS-FTD. Nat Neurosci 21(4):552-563

73. Wichterle $\mathrm{H}$ et al (2002) Directed differentiation of embryonic stem cells into motor neurons. Cell 110(3):385-397

74. Wu LS, Cheng WC, Shen CK (2012) Targeted depletion of TDP-43 expression in the spinal cord motor neurons leads to the development of amyotrophic lateral sclerosis-like phenotypes in mice. J Biol Chem 287(33):27335-27344

75. Wu LS, Cheng WC, Shen CK (2013) Similar dose-dependence of motor neuron cell death caused by wild type human TDP-43 and mutants with ALS-associated amino acid substitutions. J Biomed Sci 20:33

76. Wu LS et al (2010) TDP-43, a neuro-pathosignature factor, is essential for early mouse embryogenesis. Genesis 48(1):56-62

77. Zarei $S$ et al (2015) A comprehensive review of amyotrophic lateral sclerosis. Surg Neurol Int 6:171

\section{Publisher's Note}

Springer Nature remains neutral with regard to jurisdictional claims in published maps and institutional affiliations.
Ready to submit your research? Choose BMC and benefit from:

- fast, convenient online submission

- thorough peer review by experienced researchers in your field

- rapid publication on acceptance

- support for research data, including large and complex data types

- gold Open Access which fosters wider collaboration and increased citations

- maximum visibility for your research: over $100 \mathrm{M}$ website views per year

At BMC, research is always in progress.

Learn more biomedcentral.com/submissions 